San Jose State University

SJSU ScholarWorks

Master's Theses

Master's Theses and Graduate Research

Summer 2015

\title{
INFLUENCE OF MACROMOLECULAR CROWDING ON WATER AND MODEL REACTION EQUILIBRIA
}

Sai Sathyasree Dharmaraj

San Jose State University

Follow this and additional works at: https://scholarworks.sjsu.edu/etd_theses

\section{Recommended Citation}

Dharmaraj, Sai Sathyasree, "INFLUENCE OF MACROMOLECULAR CROWDING ON WATER AND MODEL REACTION EQUILIBRIA" (2015). Master's Theses. 4583.

DOI: https://doi.org/10.31979/etd.9k2b-x6sr

https://scholarworks.sjsu.edu/etd_theses/4583

This Thesis is brought to you for free and open access by the Master's Theses and Graduate Research at SJSU ScholarWorks. It has been accepted for inclusion in Master's Theses by an authorized administrator of SJSU ScholarWorks. For more information, please contact scholarworks@sjsu.edu. 


\title{
INFLUENCE OF MACROMOLECULAR CROWDING ON WATER AND MODEL REACTION EQUILIBRIA
}

\author{
A Thesis \\ Presented to \\ The Faculty of the Department of Chemistry \\ San José State University \\ In Partial Fulfillment \\ Of the Requirements for the Degree \\ Master of Science \\ by \\ Sai Sathyasree Dharmaraj
}

August 2015 
(C) 2015

Sai Sathyasree Dharmaraj

ALL RIGHTS RESERVED 
The Designated Thesis Committee Approves the Thesis Titled INFLUENCE OF MACROMOLECULAR CROWDING ON WATER AND MODEL REACTION EQUILIBRIA

\author{
by \\ Sai Sathyasree Dharmaraj
}

APPROVED FOR THE DEPARTMENT OF CHEMISTRY

SAN JOSÉ STATE UNIVERSITY

August 2015
Dr. Daryl Eggers
Department of Chemistry
Dr. Lionel Cheruzel
Department of Chemistry
Dr. Annalise Van Wyngarden
Department of Chemistry 


\section{ABSTRACT \\ INFLUENCE OF MACROMOLECULAR CROWDING ON WATER AND MODEL REACTION EQUILIBRIA}

by Sai Sathyasree Dharmaraj

Macromolecular crowding refers to the excluded volume in the cell by macromolecules (proteins, DNA, etc.). Crowding in the cell is relevant to the free motion of each macromolecule and may influence biological equilibria in general. The surface hydration of the crowding agents is expected to alter the average properties of water in the solution, which in turn may also affect molecular interactions. Because the living cell contains a concentration of $300-400 \mathrm{~g} / \mathrm{L}$ of macromolecules, it is crucial to study the properties of crowded solutions to understand the environment of a cell. The focus was to study the thermodynamic properties of water in solutions containing model crowding agents such as Ficoll, Dextran, PEG (polyethylene glycol), and PVP (polyvinylpyrrolidone). Crowding effects on water were measured by comparing the thermodynamic properties of reactions in dilute solution versus crowded solutions and/or by direct calorimetric methods. The results obtained from the calorimetric method were not consistent with the thermodynamic properties observed in the non-crowded solutions, but the enthalpy and solubility results indicated that crowding has a negligible effect on small molecule interactions. Future studies that adjust the sample preparation and experimental parameters for calorimetry should provide a better indication of the thermodynamic properties of water in the crowded solutions. 


\section{ACKNOWLEDGEMENTS}

My first acknowledgement goes to Dr. Eggers, my research advisor, for giving me this research opportunity along with being patient and persistent in accomplishing my goals for this research and thesis. Without his guidance I might not have advanced this far in my educational career, and I value his suggestions, thoughts, and ideas. I would also like to thank my committee members, Dr. Cheruzel and Dr. Van Wyngarden, who have provided me valuable feedback at my presentations and have been very approachable with thoughts and suggestions. I would in particular like to thank Daisy Nguyen for helping me with the collection and organization of data, especially with the solubility studies. I would like to thank my other colleagues in Dr. Eggers' lab for helping with my experiments and troubleshooting the instrument when there was an issue. I would like to thank my parents, husband, and my son for encouraging me and supporting my educational goals. 


\section{TABLE OF CONTENTS}

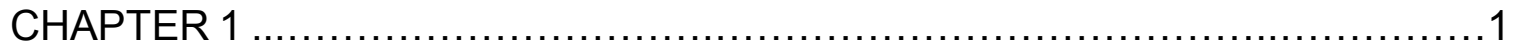

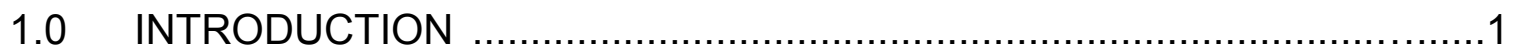

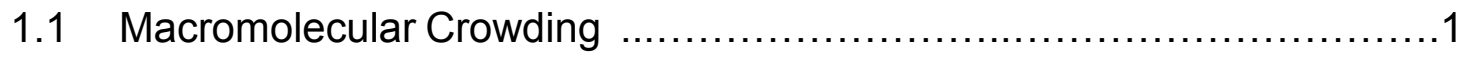

1.2 Significance of Macromolecular Crowding ..............................2

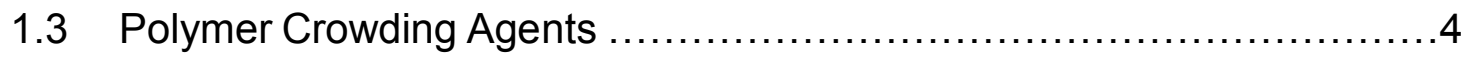

1.4 Macromolecular Crowding Effects on Protein Association \& Binding .......5

1.5 Macromolecular Crowding Effects on Protein Folding \& Stability ............

1.6 Challenges in Macromolecular Crowding \& the Variability in Inertness ...14

$1.7 \quad$ Reaction Model with Water ............................................ 18

1.8 Thermodynamics Approach to Binding Equilibria with Desolvation ........22

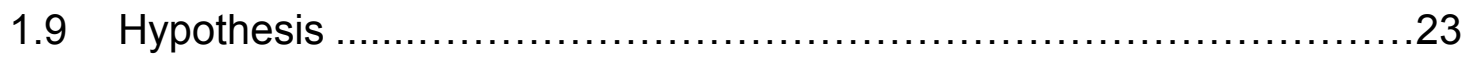

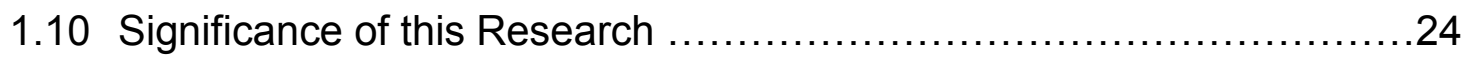

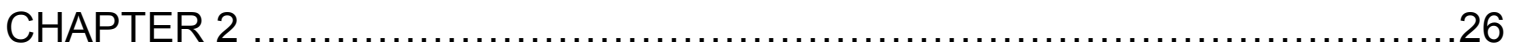

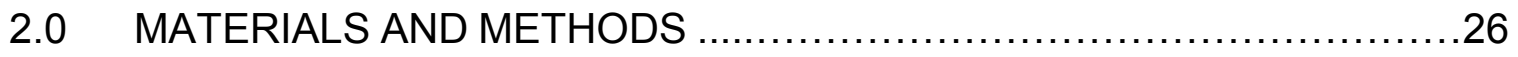

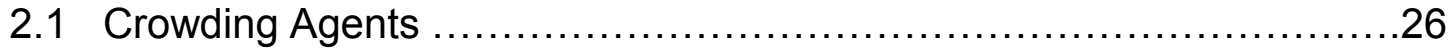

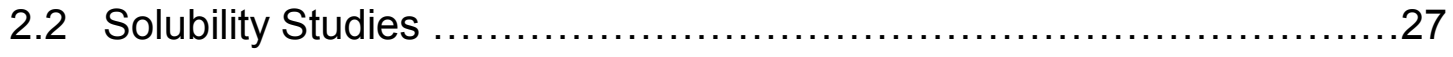

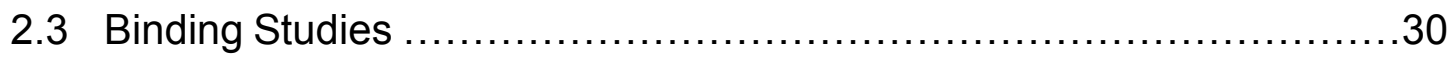

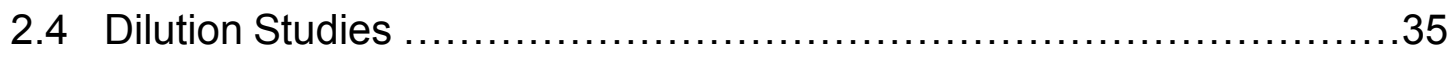

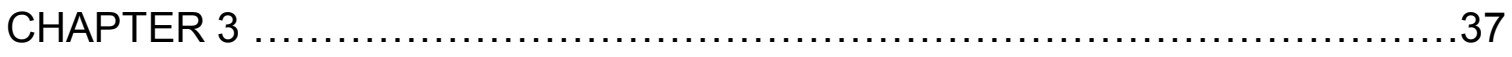

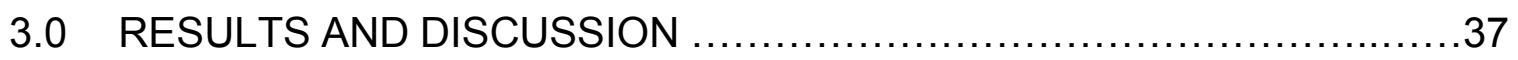

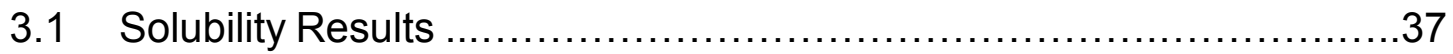

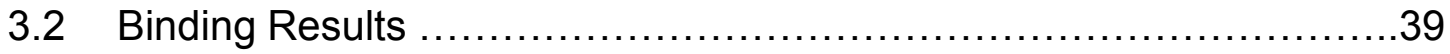

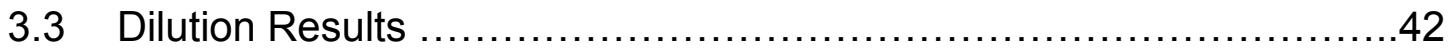




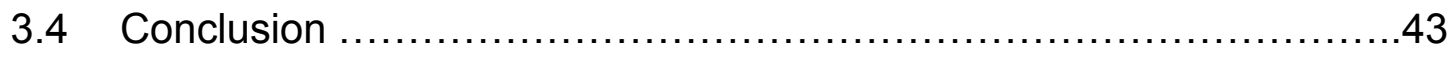

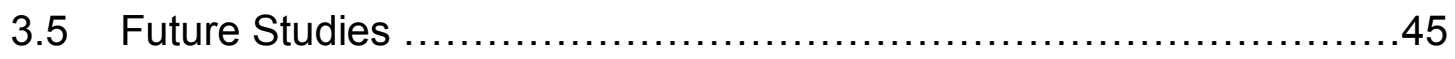

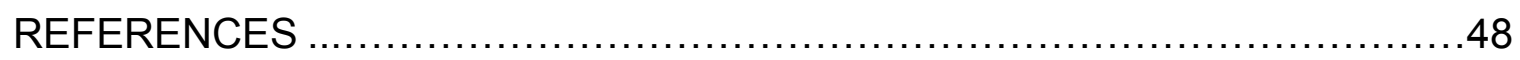

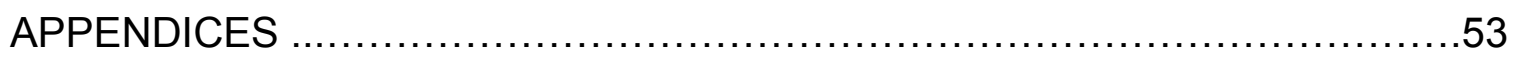

Appendix A. Solubility Results and Representative Raw Data ................53

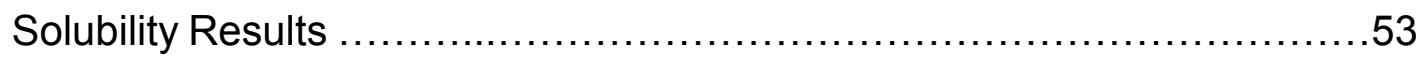

10\% Ficoll 70 Representative Data .........................................54

10\% PEG Representative Data ............................................55

10\% Dextran Representative Data .....................................57

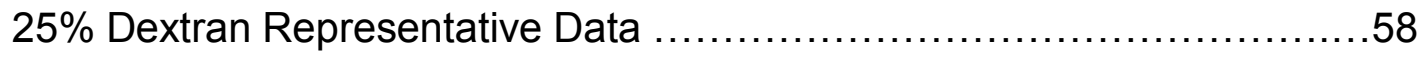

10\% PVP Representative Data ..........................................6

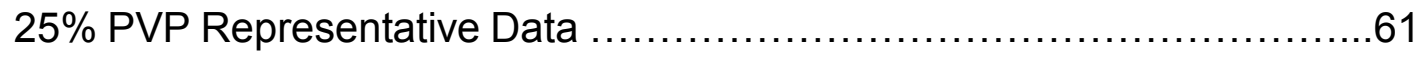

Appendix B. Binding Studies Raw Data \& Results ...........................63

10\% Ficoll 70 Detailed Data ..............................................63

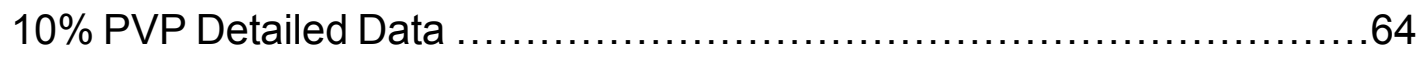

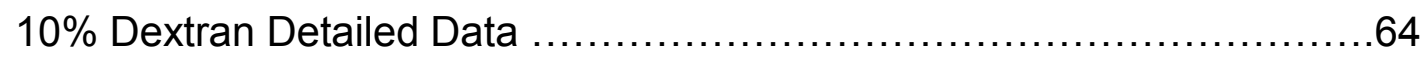

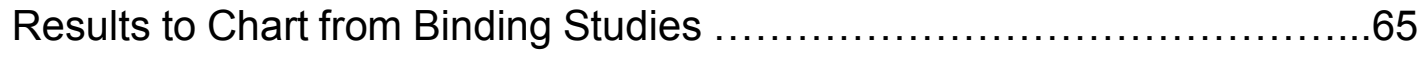

Appendix C. Dilution Studies Raw Data \& Results ...........................65 


\section{LIST OF FIGURES}

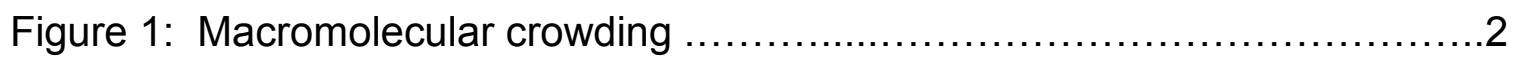

Figure 2: Structures of crowding agents used in this study $\ldots \ldots \ldots \ldots \ldots \ldots \ldots \ldots \ldots$

Figure 3: Schematic of an association reaction ................................. 6

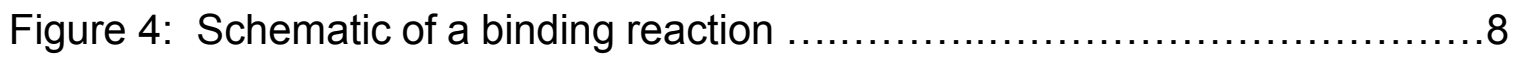

Figure 5: Schematic of a conformational equilibrium .......................... 9

Figure 6: Association reaction model with perturbed water released to the bulk

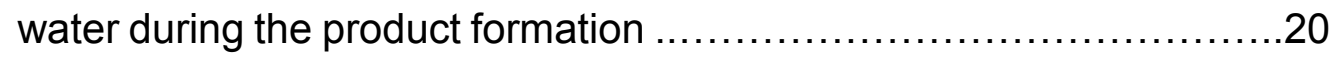

Figure 7: Schematic of protein folding in presence of secondary solute ..........21

Figure 8: Applying the desolvation model ......................................23

Figure 9: Comparison of DKP and polypeptide backbone ......................27

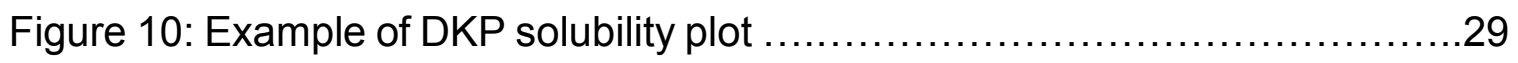

Figure 11: A sample ITC plot from an EDTA \& $\mathrm{CaCl}_{2}$ binding experiment in $10 \%$ PVP solution ..............................................................

Figure 12: A sample ITC plot of water injection into a 10\% PEG solution at $25^{\circ} \mathrm{C}$

Figure 13: DKP solubility $\left(\mathrm{mg} \cdot \mathrm{g}^{-1} \mathrm{H}_{2} \mathrm{O}\right)$ in various environments ..................38

Figure 14: Plot of -RTInK ${ }_{i}$ versus concentration of $\mathrm{Ca}^{2+}$ :EDTA complex ...........40

Figure 15: Graph of change in enthalpy $(\Delta \mathrm{H})$ of water in various crowded solutions versus temperature 


\section{LIST OF TABLES}

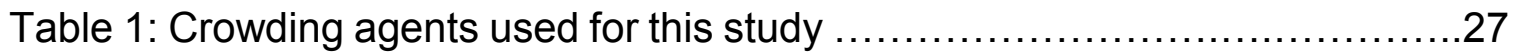

Table 2: EDTA \& $\mathrm{CaCl}_{2}$ concentrations with ITC instrument parameters ...........34

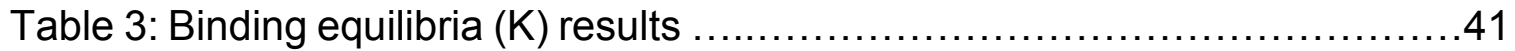




\section{CHAPTER 1}

\subsection{INTRODUCTION}

\subsection{Macromolecular Crowding}

Macromolecular crowding refers to the fact that a large volume within the cell is excluded by macromolecules such as proteins and DNA, and a living cell has a concentration of $300-400 \mathrm{~g} / \mathrm{L}$ of macromolecules (30-40\% occupancy). ${ }^{1}$ Crowding is ubiquitous for all types of cells and biological fluids including blood plasma have about $80 \mathrm{~g} / \mathrm{L}$ macromolecules. ${ }^{2}$ This densely packed environment affects the free motion of all molecules. ${ }^{1,3}$ Another term for referring to macromolecular crowding is the excluded volume effect, a phrase which stresses that the extent to which macromolecules occupy the cell volume affects the available space for all the molecules and their interactions. ${ }^{2,4}$ Also the interior of a cell is not a homogenous environment, so the molecules interact unequally within the macromolecular crowded environment. It is intriguing in that biological reactions seamlessly occur in a seemingly inconsistent and crowded environment.

The concept of macromolecular crowding was initially introduced in 1981 by Allen P. Minton, but studies regarding macromolecular crowding did not take off until 20 years later. ${ }^{3}$ Typically, cell images provided to children in grade school show the organelles with plenty of space between each other within the cell membrane, but in reality the cellular compartments do not have much empty space between each other. In Figure 1, there are two schematics that contrast 
how the inside of a cell has been viewed traditionally and a more realistic representation of the cytoplasm.
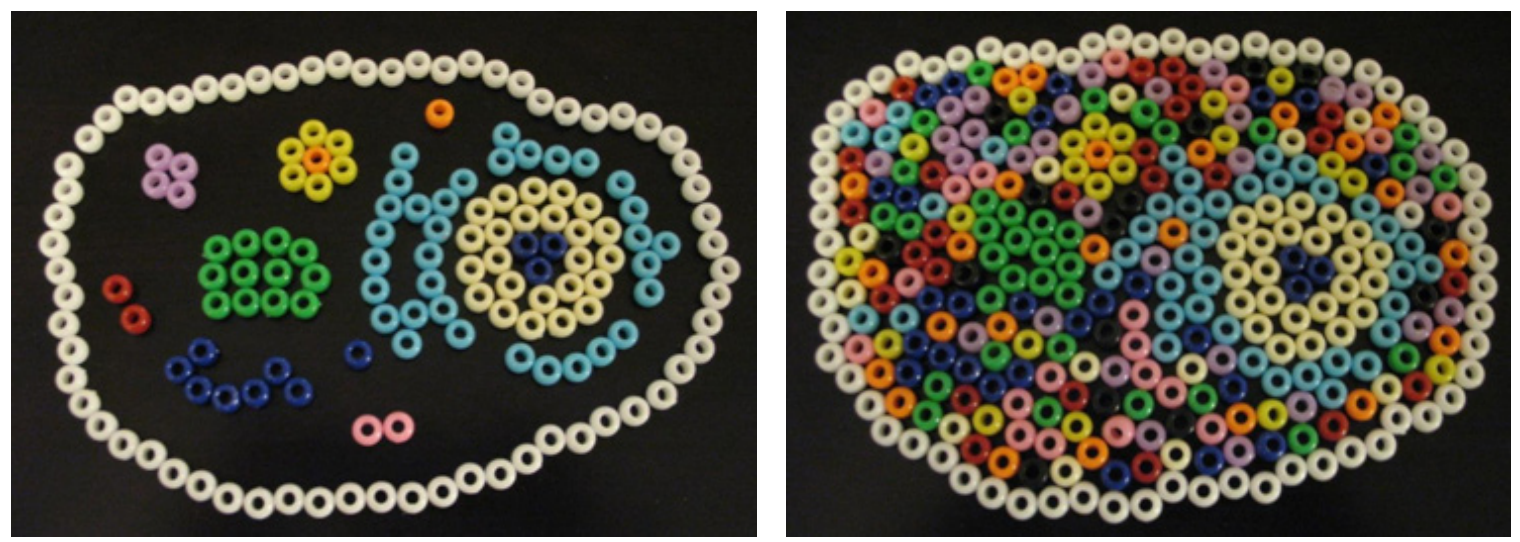

Figure 1: Macromolecular crowding. A schematic done in beads showing on the left how the inside of the cell is traditionally viewed, and on the right a view of the inside of a cell as a more realistic crowded environment.

\subsection{Significance of Macromolecular Crowding}

Macromolecular crowding can influence physiological processes such as protein folding and protein binding through random nonspecific interactions. ${ }^{1,3}$ Even though nonspecific interactions are intrinsically weak in magnitude, crowding can substantially contribute to the free energy of the physiological process and influence the final outcome. ${ }^{5}$ As an example, macromolecular crowding influences the native conformation of a protein because less space is occupied by the native state in comparison to the unfolded state. The reduced volume available in a crowded environment makes the introduction of another protein into the environment more difficult. A given protein molecule is influenced by the available volume in the environment along with the size and shape of the existing molecules. ${ }^{6}$ The hypothesis is that any conformational change that decreases volume occupancy is favored by crowded conditions. Crowding 
should play an important role in all biological processes that involve noncovalent association and/or conformational changes. ${ }^{7}$ Reactions in dilute solution might have different kinetics and equilibria from that observed in the presence of excluded volume effects, and these changes could contest the hypotheses and results of in vitro studies performed in dilute solutions. ${ }^{1}$ In general, excluded volume effects are expected to influence the following types of interactions: bimolecular association, ligand binding to a specific binding site, and the folded state of a protein.

By using thermodynamic schemes, the effects of macromolecular crowding can be determined qualitatively and quantitatively. ${ }^{1}$ There is the hypothesis that excluded volume effects reduce conformational entropy, which in turn increases the free energy and chemical potential of each molecule. ${ }^{8}$ Currently there are various computational models that calculate the quantitative effects of macromolecular crowding, especially the free energy of the nonsteric interactions. ${ }^{9}$ In order to thoroughly understand biological processes in a physiologically relevant environment, mimicking macromolecular crowding in experiments should be as commonplace as adjusting $\mathrm{pH}$ and ionic strength. ${ }^{2}$ The whole point of looking at the effects of macromolecular crowding is to gain a better understanding of how intact organisms operate in vivo, and recent studies appear to approach this goal. ${ }^{7}$ In turn, the information gleaned would result in a more in-depth model of the cellular environment to observe test molecules. If the cellular environment were not crowded, then there is the possibility we could lose 
the efficiency of biological activity and these biological activities would not occur as rapidly or occur at all. ${ }^{4}$

\subsection{Polymer Crowding Agents}

The polymers Dextran, Ficoll, polyethylene glycol (PEG), and polyvinylpyrrolidone (PVP) are typically used to mimic the crowded environment because their molecular weights are significantly large, they are highly soluble in water, and their chemical reactivities are somewhat inert. Figure 2 provides the structures of the crowding agents used in the current study.

Dextran has a linear polysaccharide backbone consisting of a long chain poly(D-glucose) and spare short branches in a more rod-like particulate. ${ }^{10}$ Ficoll 70 is more like a rigid sphere compromised of a highly branched co-polymer of two short building blocks, sucrose and epichlorohydrin. PEG is a linear polymer that is highly water soluble and has been reported to be efficient in inducing associations between molecules. ${ }^{1}$ Studies have shown that PEG does not solely exhibit excluded volume effects, but there are sometimes non-specific interactions between PEG and the test protein. ${ }^{1}$ PVP is a straight chain polymer that has recently been used as a crowding agent because of its high solubility in both water and organic solvents, as attributed to its balance of hydrophilic and hydrophobic functional groups. ${ }^{11}$ All of these polymer crowding agents have been shown to have non-specific interactions with the test reaction, especially PEG, but they are more inert than protein crowding agents. ${ }^{1,5,10}$ A possible drawback to using these polymer crowding agents is that they do not generate an 
ideal crowded environment as found in biological fluids because they do not mimic the short range attractions that may exist between multiple macromolecules. ${ }^{1}$

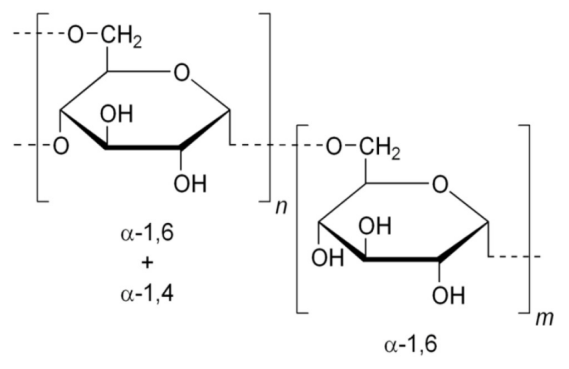

Dextran<smiles>CCC(C)(C)N1CCCC1=O</smiles>

Polyvinylpyrrolidone<smiles>CCOCCCO</smiles>

Polyethylene Glycol

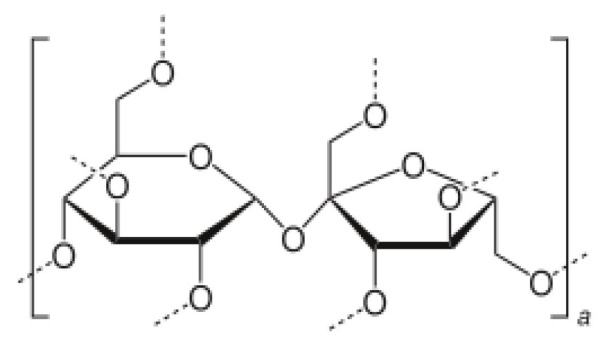

Ficoll

Figure 2: Structures of crowding agents used in this study.

\subsection{Macromolecular Crowding Effects on Protein Association \& Binding}

Crowding could positively influence two molecules that undergo dimerization

if the dimer is more compact than the two separate molecules, but if the dimer's shape excludes more volume than the initial monomers, then crowding could inhibit the bimolecular association. ${ }^{1}$ Figure 3 provides a schematic of two molecules undergoing association and forming a more compact product. The reaction rate could also be affected by macromolecular crowding if the concentration of the crowded environment is high enough to slow down the 
encounter rate of two molecules for association, even if the product from the association will results in a more compact formation. ${ }^{2}$ Yet the influence of crowding on reaction rate is not straight forward, and the rate is dependent on the reactants along with the concentration and properties of the crowding agents.

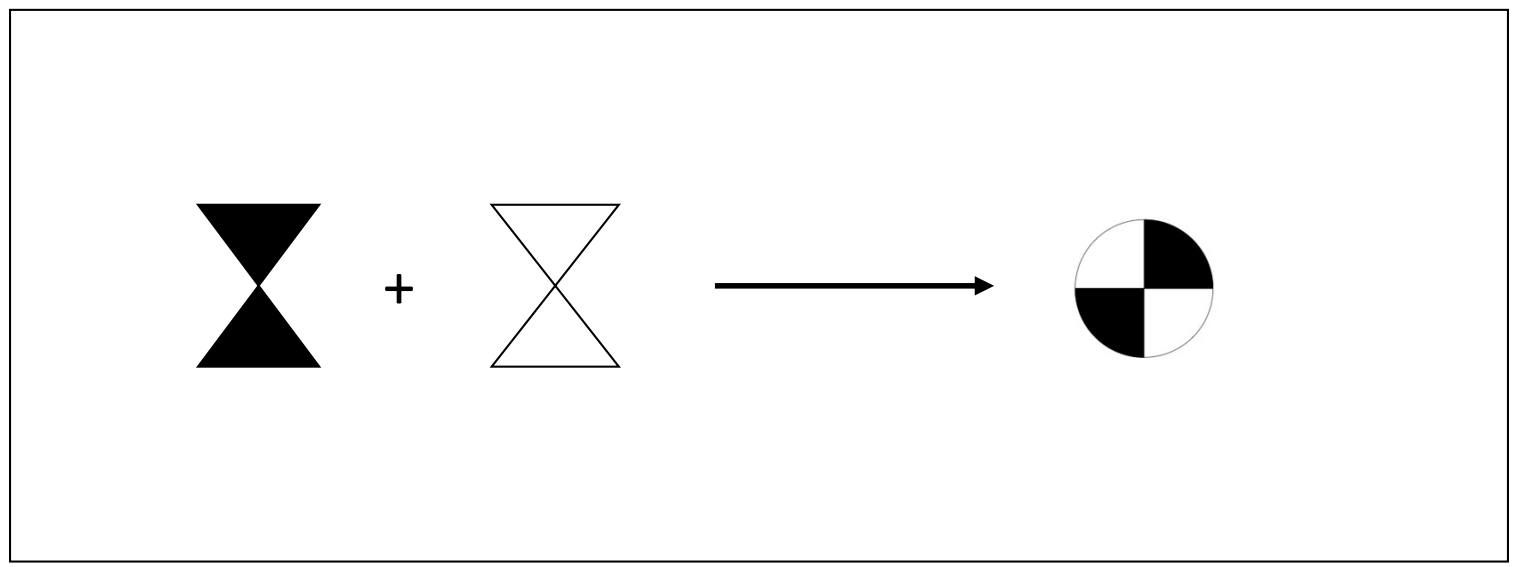

Figure 3: Schematic of an association reaction. The two monomers on the left combine to form a more compact product as exhibited on the right.

Crowding could have negative and positive effects on the assembly and function of proteins. ${ }^{7}$ A negative effect would be that crowding slows the reaction rate, with the macromolecules physically blocking the reactants from assembling, or promoting aggregation of the protein instead of forming the final product. As a positive effect, even though crowding could enhance aggregation of proteins, crowding also could enhance the activity of molecular chaperones by encouraging their association reactions with the partially folded protein.

An early study was performed in a crowded environment of Ficoll 70 or bovine serum albumin (BSA) in which a special chaperone (PDI) assisted in lysozyme refolding. ${ }^{12}$ The refolding rate of lysozyme, observed using a fluorescence assay, is faster in the crowded environment with the chaperone 
assistance than in the dilute environment. ${ }^{12}$ Without the chaperone the crowded environment could not solely assist with the lysozyme refolding and led to aggregation, but what is interesting is that crowding enhanced the activity of the chaperone.

There has been an observation that macromolecular crowding can help stabilize nucleotide hybrids during polymerase chain reaction (PCR) experimentation. ${ }^{13}$ Real-time PCR in the presence of macromolecular crowding showed that complementary DNA-DNA and DNA-RNA hybrids were more stable at increased temperatures and that degradation of the Taq polymerase was minimized. ${ }^{13}$ Each crowding agent used individually during the experimentation (Ficoll 70, Ficoll 400, and polyvinylpyrrolidone 360) increased the melting temperature of the hybrid DNA by approximately $1^{\circ} \mathrm{C}$, but, in the presence of all three crowding agents, the melting point increased by approximately $8^{\circ} \mathrm{C}$, higher in comparison to the non-crowded control. ${ }^{13}$ The higher thermal stability indicated a significant computed increase in efficacy of nucleotide hybridization in the presence of macromolecular crowding (3-fold increase), especially a mixed environment of multiple crowding agents (6-fold increase). ${ }^{13}$ The mixed environment provided by multiple crowding agents is a better indication of the inhomogeneous physiological conditions, which makes for more fascination regarding the increased stability in comparison to using homogeneous crowding agents. 
Other than dimerization, there are also binding interactions in which a ligand (a small molecule) binds to a large protein (macromolecule), and macromolecular crowding could enhance ligand binding to the protein if the conformational change is more compact than the individual species. ${ }^{1}$ Figure 4 shows for a schematic of a ligand binding to a protein.

The enzymatic activity of phosphoglycerate kinase, glyceraldehyde 3phosphate dehydrogenase, and acylphosphatase were studied in the presence of Ficoll using Michaelis-Menten kinetics. ${ }^{14}$ The crowded environment did not significantly alter the observed kinetic activity of the glycolytic enzymes in comparison to a dilute environment. ${ }^{14}$ This means that crowding did not enhance the enzymatic activity, but also means that the crowding and increased viscosity did not significantly alter the rate limiting step.

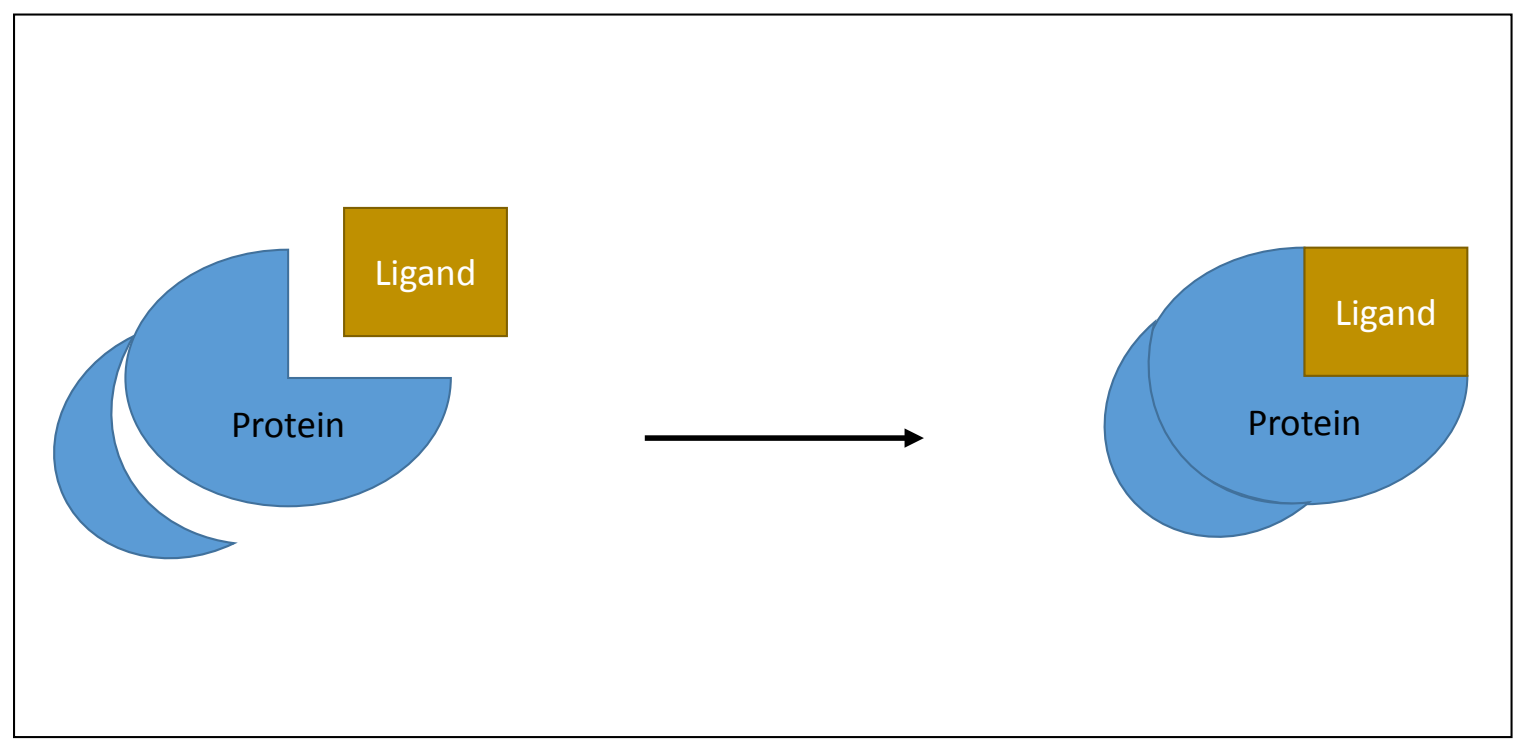

Figure 4: Schematic of a binding reaction. The ligand binds to the protein on the left to form a more compact conformation, as exhibited on the right. 


\subsection{Macromolecular Crowding Effects on Protein Folding \& Stability}

Macromolecular crowding can help lower the energy barrier for the protein to fold into a favored conformation if the folded state occupies less space in the environment, but if an intermediate state of a protein conformation excludes less volume than the final conformation, then crowding will not lower the energy barrier to the final conformation. ${ }^{1}$ There are various intermediate states of differing conformation along the folded pathway to the globular native state, and macromolecular crowding can influence all of the different transitions. ${ }^{8}$ Figure 5 is a schematic of an unfolded protein adopting its native state for which less surface area of the protein is exposed to the cellular environment corresponding to a more compact structure.

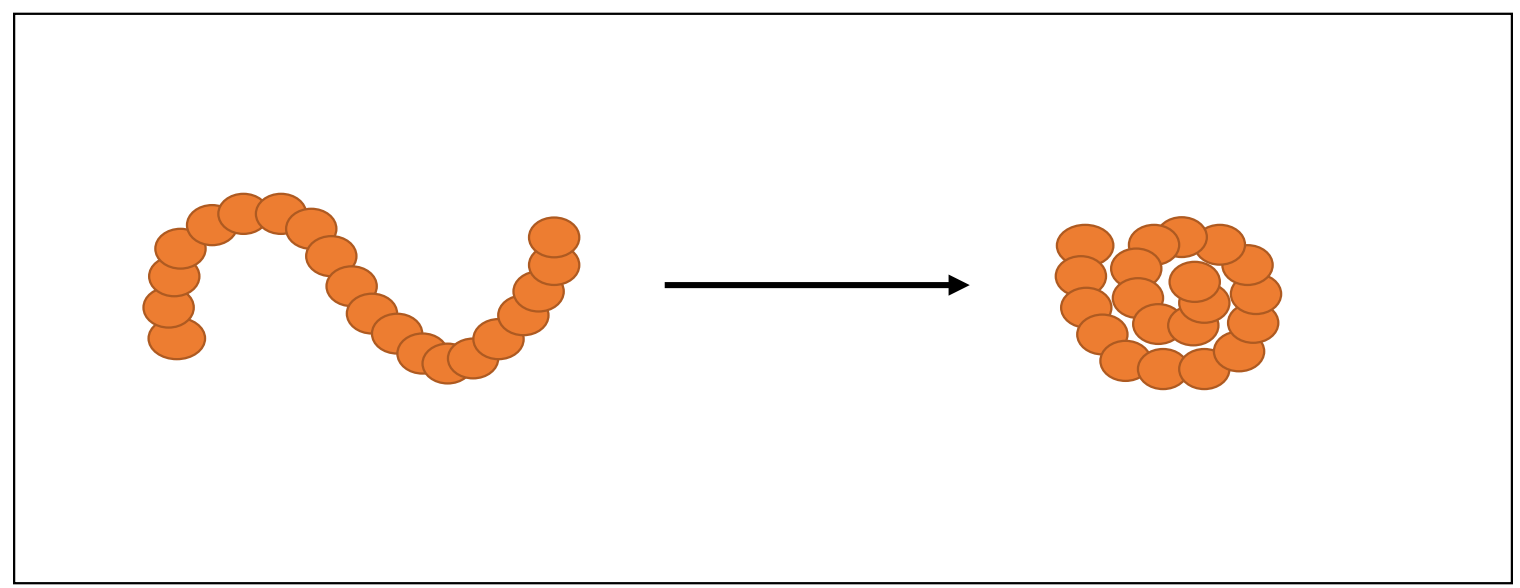

Figure 5: Schematic of a conformational equilibrium. The unfolded protein on the left folds into its native state on the right.

An early study in this field looked at the effects of macromolecular crowding by observing the refolding of reduced and oxidized lysozyme in multiple crowded environments using Dextran, Ficoll 70, ovalbumin, and BSA. ${ }^{15}$ The oxidized lysozyme (with disulfide bonds intact) refolded in the presence of the crowding 
agents in yields close to $100 \%$, but the refolding of the reduced lysozyme was minimal, and the result was interpreted as a consequence of protein aggregation instead of refolding into the native state. ${ }^{15}$ This is a clear example of macromolecular crowding not enhancing protein folding for the reduced lysozyme. However, the authors noted that the aggregation may also be favored by crowding, and this explains why it is important to understand the influence of crowding on the protein to either fold or aggregate.

Another study was designed to observe the protein transition process for the unfolded to folded state of lysozyme using near-UV and far UV-circular dichroism (CD) in various concentrations of Dextran. ${ }^{16}$ By increasing the concentration of Dextran in the solution, the structure of lysozyme was observed to shift to a more compact globule-like state by $\mathrm{CD}$, indicating that macromolecular crowding should indeed favor the most compact state. ${ }^{16}$ In this case, crowding enhanced protein folding, which is consistent with the hypothesis that a more compact state is favored.

Folding of the protein Ribonuclease A has also been studied for macromolecular crowding effects. ${ }^{17}$ Circular dichroism spectroscopy, fluorescence correlation spectroscopy, and NMR spectroscopy were used to measure the folding and compact state of ribonuclease A in polyethylene glycol (PEG) and Ficoll solutions. Ribonuclease A went from an unfolded state to its folded and compact native conformation better with the addition of 35\% PEG 20000 or Ficoll 70 in comparison to the absence of the crowding agents. ${ }^{17}$ Also, 
the compactness of an inert macromolecule, fluorescently labeled PEG, was analyzed in a solution of unlabeled PEG or Ficoll, and the results indicated that an increase in concentration of either of the crowding agents caused the size of the fluorescently labeled PEG to decrease significantly. ${ }^{17}$ These results suggest that macromolecular crowding plays a critical role in folding stability and compactness of macromolecules in general.

The apo derivative of $\alpha$-human lactalbumin (apo-HLA), which lacks a calcium cofactor, was studied for protein stability in crowded environments such as Ficoll 70, Dextran 70 and polyethylene glycol (PEG) 2000 because apo-HLA can form a stable compact globule conformation. ${ }^{10}$ Also, a lack of direct interactions between the crowding agent and the apo-HLA was confirmed, with the exception of PEG 2000. ${ }^{10}$ Using intrinsic fluorescence, the thermal stability of apo-HLA, at the same apo-HLA concentration, increased in the presence of Ficoll 70 or Dextran 70, but decreased in the presence of PEG 2000 in comparison to dilute environments. ${ }^{10}$ This shows that the chemical properties of the crowding reagent are similarly important in determining the stabilization of a protein, and excluded volume effects can enhance protein folding to a compact conformation. The outcome of this experiment would be interesting if a test protein that did not easily fold into a stable compact state was tested alongside the original experiment.

The binding free energies of two proteins, $\varepsilon$ - and $\Theta$ - subunits of the Escherichia coli DNA polymerase III holoenzyme (Pol III) were studied in the 
presence of the crowding agents Dextran or Ficoll using a fluorometer. ${ }^{18}$ In the presence of increased molecular mass of Dextran or Ficoll, the binding energy also increased by approximately $1 \mathrm{kcal} / \mathrm{mol}$, having a stabilizing effect. ${ }^{18}$ Even though $1 \mathrm{kcal} / \mathrm{mol}$ may seem to be a modest influence from macromolecular crowding, the effect would be cumulative for oligomeric proteins in vivo.

One critical item to understand about crowding is that it could simultaneously stabilize a protein conformation and enhance the efficiency of formation, even though it might slow the rate of the formation. ${ }^{5}$ Excluded volume effects can influence the stability or destability of a protein, and make it possible for the protein to resist denaturation caused by a change in temperature or by addition of a denaturant. In addition, macromolecular crowding could minimize aggregation by preventing denatured protein chains to entangle, but crowding could also enhance aggregation if intermolecular interactions are favored over intramolecular interactions..$^{5,8}$

The formation of nonphosphorylated Tau-(244-441) filament, which is important in the pathogenesis of neurodegenerative diseases, has been studied in the presence and absence of Ficoll 70 and Dextran 70 by measuring the fluorescence intensity with a luminescence spectrometer. ${ }^{19}$ Consistently, the formation of nonphosphorylated Tau-(244-441) filaments increased in the presence of Ficoll 70 or Dextran 70 crowding agents in comparison to the absence of the crowding agents. ${ }^{19}$ The results indicate that crowding is a critical 
parameter to consider for studying neurodegenerative diseases, especially if crowding enhances the disease.

Human apolipoprotein C-II (ApoC-II) has been found to form amyloid fibrils under the influence of macromolecular crowding. ${ }^{20}$ Excluded volume effects on ApoC-II were studied using fluorescamine reactivity and Dextran as the crowding agent because no association effects between ApoC-II and Dextran was observed. The lack of association effects between ApoC-II and Dextran was confirmed by looking at the conductivity of the buffer with the addition of Dextran and by performing sedimentation experiments on $\mathrm{ApoC}-\mathrm{II}$ in the presence and absence of Dextran. The presence of the Dextran accelerated the formation of amyloid fibrils from ApoC-II in comparison to the absence of Dextran, confirming that the kinetics of aggregation is subject to excluded volume effects. ${ }^{20}$

A natively disordered protein, $\alpha$-synuclein, is associated with Parkinson's disease and its structure has been observed to be stabilized by macromolecular crowding using NMR in vivo (inside the Escherichia coli cells) and in vitro (in the presence of bovine serum albumin). ${ }^{21}$ The results from the in vivo and in vitro trials indicate that macromolecular crowding stabilizes a compact but disordered a-synuclein structure in comparison to the temperature-dependent changes observed in dilute solution. ${ }^{21}$ The study led to the conclusion that excluded volume is solely capable of stabilizing the protein since $\alpha$-synuclein stabilized in vivo and in vitro studies. In another study, an increased rate of protein aggregation and formation of amyloid fibrils was observed in vitro using a 
fluorescence assay in various types of crowded environments including PEG, Ficoll, Dextran, and BSA solutions. ${ }^{22}$ Each of the crowded environments accelerated the fibrillation of $\alpha$-synuclein in comparison to the control environment, and the rate of fibril formation increased with increasing polymer concentration and with increasing length of polymer. ${ }^{22}$ These results imply macromolecular crowding has an impact on amyloid fibrils formation, though in the second study the samples were mechanically agitated on a shaker for many hours to initiate aggregation..$^{21,22}$ In the scenarios in which crowding promoted the formation of fibrils, the issue is raised as to why the crowding can cause this when not everyone is affected by an amyloid-associated disease.

\subsection{Challenges in Macromolecular Crowding \& the Variability in Inertness}

It is difficult to mimic the exact environment of macromolecules in the cellular environment in an experimental crowding solution because the viscosity of the solution is tough to handle in experimentation. ${ }^{7}$ The use of highly concentrated cell extracts as the crowding environment has been considered, but then the effects of that environment on the test molecule could be due to other non-crowding-related issues such as specific interactions, hydrolyase activity, and the possible presence of denatured proteins. The transport of molecules in and out of the cell along with metabolism can also affect the extent of macromolecular crowding and the cells' overall volume, and these variables are difficult to mimic by in vitro experimentation. 
Crowding effects are a challenge to study in the cellular environment because it is difficult to confirm if the results are solely from excluded volume effects or from weak associations between the test protein and one or more neighboring molecules. ${ }^{23}$ The "perfect" crowder has yet to be determined, and the field still debates whether the importance is to focus on excluded volume effects or to include interactions between the crowder and the test protein in the analyses.

A recent study looked at the potential chemical interactions between the crowded environment and test protein which the authors termed soft interactions. ${ }^{24}$ Varying concentrations of PVP, along with a small globular test protein, chymotrypsin inhibitor $2(\mathrm{Cl} 2)$, were analyzed using NMR-detected amide proton exchange. The chemical shifts of the protein residues were compared in various concentrations of PVP, and a significant chemical shift in the signal was observed as the concentration of PVP increased. ${ }^{24}$ This increase in chemical shift of the protein was interpreted to be weak chemical interactions between PVP and the protein. Excluded volume effects are not likely to be the cause of conformational changes in the test protein when more of the protein becomes exposed to the PVP, presumably occupying more volume instead of less.

BSA and hen egg-white lysozyme are protein based crowding agents that were used to provide more of a physiologically-relevant macromolecular crowding model for the study of chymotrypsin inhibitor $(\mathrm{Cl} 2)$ using NMR. ${ }^{25}$ An 
observation was that the protein-based crowding agents have destabilizing effects on $\mathrm{Cl} 2$ structure which contradicts the results obtained with polymer crowding materials such as PVP or Ficoll $70 .{ }^{25}$ These authors concluded that the role of soft interactions in macromolecular crowding needs to be taken into consideration during experimentation. ${ }^{24}$ The physiological relevance of this study is that the structure of a protein can be tuned by the surrounding molecules, and the change can either be stabilizing or destabilizing. ${ }^{25}$ This is intriguing because the studies hinted that the protein needs to be in the right environment at the right time to be stable, and raised the curiosity as to how the cellular environment is capable of making that happen.

The stability of ubiquitin has been observed using NMR with different synthetic crowding agents, such as PVP and Ficoll, and with protein crowding agents, such as BSA and lysozyme. ${ }^{26}$ When comparing the thermal stability of ubiquitin in the various crowded environments, the results indicated that the presence of PVP or Ficoll was comparable to a dilute environment, whereas the stability of ubiquitin in BSA or lysozyme decreased in comparison to the protein in a dilute solution. ${ }^{26}$ Based on these results, there is difficultly in generalizing an overall effect due to macromolecular crowding, and the results appear that chemical interactions may be playing a critical role.

In another study, results were determined that protein aggregation was enhanced not only from excluded volume effects, but also from the viscosity of the solution and from non-specific interactions between the macromolecules and 
protein. ${ }^{27}$ Rigid polysaccharides such as hydroxylpropyl celluloses were compared with more flexible polysaccharides such as Dextran to model macromolecular crowding effects on the formation rate of amyloid fibrils of insulin and $\alpha$-synuclein. NMR, electron microscopy, CD, and viscosity measurements were obtained, and the results showed differences in aggregation rate that were dependent on the flexibility of the polysaccharides. ${ }^{27}$ In this study the rigid polysaccharides did not enhance the rate of formation of amyloid fibrils as much as the flexible polysaccharides, causing the authors to ponder the macromolecular environment of a healthy cell versus a diseased cell.

To summarize, in a crowded environment, the macromolecules could interact with each other and/or with the molecules being studied by soft chemical interactions, as well as hard non-specific steric interactions (i.e. excluded volume effects). ${ }^{28}$ These interactions could have a significant influence on biochemical processes. There is no known crowding material that is completely inert to protein interactions with all proteins, but, if the objective is to study the cellular effects of crowding, then looking solely at excluded volume effects would not present the complete picture because the cellular environment is not inert. Differences in biochemical reactivity in vitro versus in vivo cannot be attributed only to the presence of excluded volume effects because, in the environment of the cytoplasm, there are many other attributes that might not uniformly affect biochemical reactions. ${ }^{29}$ It is difficult to mimic the complex cellular environment using crowding agents, even with a solution of mixed crowding agents, and 
crowding experiments are even more difficult to design in vivo to study macromolecular crowding effects, but some scientists are taking up the challenge and performing studies inside intact cells and tissues. ${ }^{20,28}$ The best case scenario would be to study the biological reaction within the live cell without disrupting the cellular system, but the limitations in technology do not make this type of experimentation readily available.

\subsection{Reaction Model with Water}

Paracelsus in the $16^{\text {th }}$ century said, "Water is the matrix of the world and of all its creatures". ${ }^{30}$ Even though there is common knowledge that life cannot be sustained without water, water has been neglected as an active component in the cellular environment. Numerous publications regarding biological molecules and processes ignore the importance of water. ${ }^{31}$ Water is not simply a backdrop for biological processes, but interacts with the biomolecules in intricate, subtle, and crucial ways. ${ }^{30}$ The hydrogen bonds from water can control protein folding, structure, and activity by forming clusters on the surface of the protein, depending on the hydrogen bonding propensities of the exposed amino acid residues, and influence the structure throughout protein folding. ${ }^{31}$ Protein conformational changes are accompanied by release of water molecules, which in turn affects the viscosity and diffusive properties of the intracellular water.

There is a growing interest in the interaction of water at hydrophobic and hydrophilic surfaces, but there is no certainty as to how the interactions affect the thermodynamic properties of water and the overall reaction. ${ }^{32}$ Water can be 
characterized as individually isolated molecules, small clusters, or larger networks, and water can function with all the above mentioned properties in one environment. ${ }^{31}$ Introduction of the solvent molecules and their thermodynamic properties can be used to interpret changes in the solubility of model solutes. ${ }^{33}$

There are multiple types of water interactions possible in the reaction environment leading to perturbed water molecules near the surface of the solutes that differ in arrangement and orientation in comparison to the bulk water. ${ }^{34}$ In the Eggers model, bulk water is not the same as neat water, water that is not in the presence of any solutes, because the model includes water near the secondary solutes, in addition to water not directly interacting with any surface. ${ }^{34}$ Figure 6 shows a reaction model that includes perturbed water as a subset of the bulk water.

Typically, when calculating the total free energy change of a reaction, the energy from the weak non-covalent water interactions might be insignificant, but in the case of biological reactions the energy contribution from weak forces, especially the change in free energy of water, could greatly influence the conformation and binding equilibria of macromolecules. ${ }^{34}$

The desolvation energy can be defined as the change in energy of the water released to the bulk phase upon formation of the product. ${ }^{34}$ If the desolvation energy is incorporated into the Gibbs free energy of the reaction (which is the overall free energy of the products minus the reactants), thereby including water in the balanced reaction might shift the predicted equilibrium. 
The desolvation energy model includes the free energy of the bulk water as a variable (co-product) in the thermodynamic scheme. Refer to Equation 1 below for the desolvation energy model that includes water in the reaction equilibria. Refer to Equation 2 for the calculation of the desolvation energy for a binding reaction.

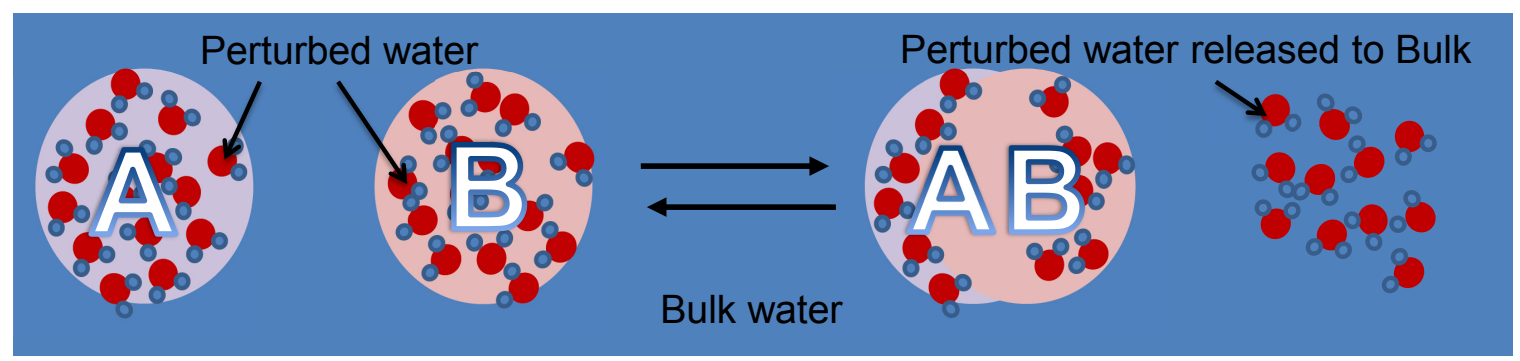

Figure 6: Association reaction model with perturbed water released to the bulk water during the product formation. In this case, the reaction is a simple binding event to form a complex, $A B$.

Equation 1: Desolvation Energy Model: $\Delta G^{r x n}=G^{A B}-\left(G^{A}+G^{B}\right)+\Delta G^{H 2 O}$ Where:

$G^{A} \quad=$ Free energy of reactant $A$

$G^{B} \quad=$ Free energy of reactant $B$

$G^{A B} \quad=$ Free energy of product

$\Delta G^{H 2 O}=$ Desolvation energy

Equation 2: Desolvation Energy $=\Delta \mathrm{G}_{i}^{\mathrm{H} 2 \mathrm{O}}=\hat{\mathrm{n}} \mathrm{C}^{\mathrm{AB}}\left(\overline{\mathrm{G}}_{i}^{\text {bulk }}-\overline{\mathrm{G}}^{\text {solv }}\right)$ Where:

$\hat{n}=$ the number of moles of water displaced per binding event

$\mathrm{C}^{\mathrm{AB}}=$ concentration of the complex product

$\overline{\mathrm{G}}_{\mathrm{i}}^{\text {bulk }}=$ the average free energy of bulk water per mole of bulk water in a given solution

$\overline{\mathrm{G}}^{\text {solv }}=$ the average free energy of the perturbed water per mole of perturbed water in the solvation sphere of the reactant that is displaced on product formation

The desolvation energy model can be applied to protein folding equilibria which may be viewed as intramolecular binding reactions. ${ }^{34}$ Refer to Figure 7 for a schematic of protein folding. The blue area is the bulk water, the white area the perturbed water, and the yellow area is the perturbed water that is released 
into the bulk water after the protein has folded. If the yellow perturbed water is not in a favorable configuration, then the desolvation energy could act as a driving force for the folding as described in scenario (a) of Figure 7 . If a secondary solute is added to the bulk water and increases the average free energy of the bulk water, then this could reduce the driving force of the desolvation energy, making the overall energy of folding less favorable and shifting the protein equilibrium to the unfolded state, as described in scenario (b) of Figure 7. For example, urea is known to denature proteins, and the assumption is that urea is directly interacting with the protein to unfold it. In contrast, the desolvation model views urea as a secondary solute that increases the bulk water energy to be significantly unfavorable, which will make the desolvation energy more positive and may change $\Delta G^{r \times n}$ to favor the unfolded protein instead of the folded protein.
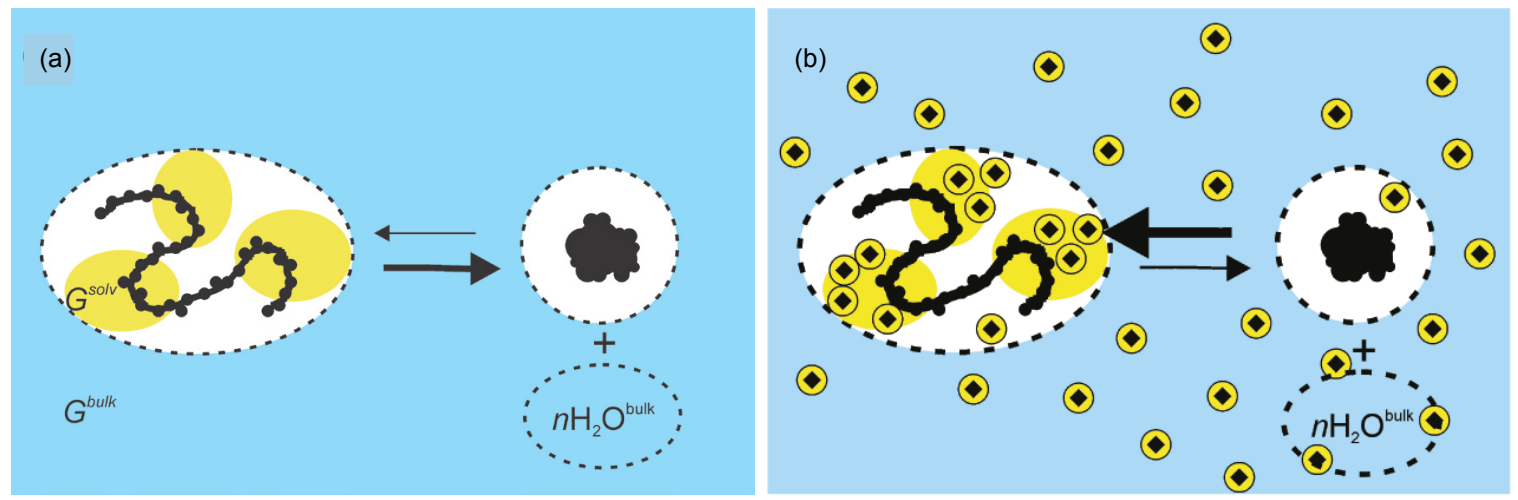

Figure 7: Schematic of protein folding in presence of secondary solute. (a) Schematic of protein folding depicting the bulk water (in blue) and perturbed water (in white \& yellow). (b) Schematic of protein folding with the presence of a secondary solute (the black diamond in the yellow circle), and the desolvation energy driving the protein to the unfolded state (reprinted with permission from Dr. Eggers). ${ }^{34}$ 


\subsection{Thermodynamics Approach to Binding Equilibria with Desolvation}

In classical thermodynamics the equilibrium constant $(\mathrm{K})$ is assumed to be the same value regardless of the reactant concentration, but the standard state change in free energy is known to be a function of the specific solution conditions, which implies $\mathrm{K}$ is a function of each solution. The experimental reality is that $\mathrm{K}$ is sometimes a function of concentration of the reactants and often influenced by the presence of secondary solutes in the solution. ${ }^{35}$ Using the desolvation model depicted in Figure 8, with the proposed Equation 3, a better understanding may be gained on the experimental reality of the binding energy and how to calculate the desolvation energy and overall free energy for a reaction in the presence of different secondary solutes. If the desolvation energy model holds as given by Equation 3, then the desolvation energy is a constant for a given solution condition and is calculated as the slope when -RTInK is plotted against reactant concentration. At very low reactant concentrations, the value of $-R \ln K$ should become independent of the solution conditions and lead to one point, which is the standard state free energy of that particular reaction. 


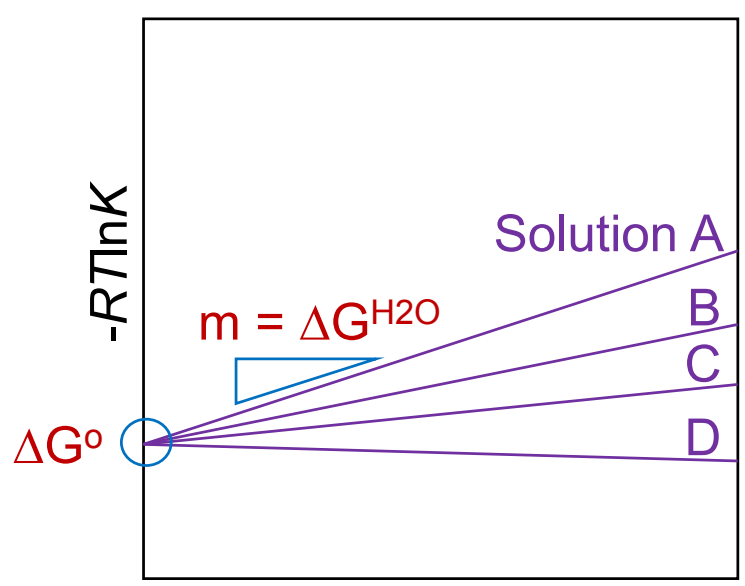

[Reactant], molality

Figure 8: Applying the desolvation model. Application of desolvation model to an aqueous reaction in the presence of different co-solute, A-D, the lines are a linear relationship between $-R T n K$ versus the concentration in molality (everything will be based on the same mass of water). The slope of the lines will be the desolvation energy, and the $y$-intercept of all the lines will be the standard state free energy of the model reaction.

Equation 3: $\Delta G^{\circ}=-R T \ln K_{i}-[A B]_{i}^{e q} \Delta G_{i}^{H 2 O}$ Where:

$\Delta G^{\circ} \quad=$ standard free energy of the reaction

$R=8.3144621 \mathrm{Joules} / \mathrm{mol} \cdot \mathrm{K}$ (ideal gas constant)

$T \quad=$ temperature in Kelvin

$[A B]_{i}^{\text {eq }}=$ concentration of product complex in molality

$K_{i} \quad=$ binding affinity of reaction

$\Delta G_{i}^{H 2 O}=$ desolvation energy of the reaction in a particular secondary solute environment

\subsection{Hypothesis}

So far, in models on macromolecular crowding, water molecules are not considered explicitly in the reaction, but discounting the solvent might be unrealistic in assuming that the solvent is not involved. ${ }^{4}$ Changes in the free energy of water may play an important role in biological equilibria in the cell along with macromolecular crowding effects. It is critical to study the thermodynamic properties of water in a crowded environment because nearly all water in the 
cellular environment is perturbed due to the concentration of solutes, with only 1 $2 \mathrm{~nm}$ of distance between macromolecules. ${ }^{30}$ This implies that only 4-8 water molecules can occupy the space between macromolecules. The thermodynamic equations (Equations1-3) described here are different from other equations in the literature because they include a term for the bulk and solvation water from the reactions, and because the bulk water is treated as a variable dependent on the solute concentration and the surface properties of the solute. This approach emphasizes the importance of studying the energy of the water interacting in a crowded environment and how the water energetics might affect biological reactions and conformational changes. The crowding agent used in our studies may be referred to as the secondary solute, and the model species that is used to measure solvent-dependent changes in solubility and binding may be referred to as the primary solute or reactant.

\subsection{Significance of this Research}

The outcome of this research can provide further insight on how well the thermodynamic framework can describe biological reactions, including the influences of water and the crowded environment. The results could explain the role of water in the reaction model and how water is influenced by the crowded environment. Future in vitro experimental approaches and views could be altered if this research reveals the significance of water interactions in the context of crowded solutions. 
As a secondary benefit, studying the influence of macromolecular crowding and the properties of water could enhance the design of protein formulations for biopharmaceuticals. ${ }^{36}$ By including macromolecular cosolutes as part of the protein formulation, protein stability and efficacy could benefit.

Biopharmaceutical companies should be interested in excluded volume effects to help gain a better understanding of their products, especially the conformational state of the molecule for best efficacy.

Studying macromolecular crowding is important because crowding might explain protein-aggregation-related diseases such as Alzheimer's and Parkinson's by considering the changes in intracellular crowding that occur with aging. ${ }^{18}$ Macromolecular crowding could be important in the pathogenesis of neurodegenerative diseases if crowding is responsible for accelerating the misfolding of amyloidgenic proteins. ${ }^{19}$

Understanding the influence of macromolecular crowding and the properties of water could also benefit research on carcinogenesis. Carcinogenesis could possibly be triggered by changes in hydration in the intracellular environment. ${ }^{31}$ Cancer cells have more free water in comparison to normal cells, and, as the degree of cell hydration increases, so does the malignancy of the cancer cell. ${ }^{31}$ The increase in free water in the cancer cells may give these cells a competitive advantage in consuming nutrients in comparison to the normal cells. 


\section{CHAPTER 2}

\section{MATERIALS AND METHODS}

\subsection{Crowding Agents}

Table 1 provides the specific information in terms of reagent vendor, lot number, and molecular weight of each crowding agent used. Structures of crowding agents are provided in Figure 2. Each crowding agent was prepared at $100 \mathrm{~g} / \mathrm{L}(10 \% \mathrm{wt} / \mathrm{wt})$ in Tris hydrochloride buffer solution for solubility and dilution experiments, and MES buffer for binding experiments. Additionally, and for solubility studies, the crowding agents Dextran and PVP were prepared at 250 $\mathrm{g} / \mathrm{L}(25 \% \mathrm{wt} / \mathrm{wt})$. For solubility studies and dilution studies, the crowded solutions were prepared at room temperature using $10 \mathrm{mM}$ Tris hydrochloride buffer at $\mathrm{pH}$

7.4. For binding studies the crowding solutions were prepared at room temperature using $150 \mathrm{mM}$ MES buffer adjusted to $\mathrm{pH}$ 6.2.

The reason polymer crowding agents were used instead of protein crowding agents such as bovine albumin serum (BSA) was because the synthetic polymers were cheaper and had a lower viscosity, which made accurate pipetting easier, especially for isothermal titration calorimetry experimentation. ${ }^{7}$ Also these polymers have been used in multiple published studies to mimic macromolecular crowding, and they were readily available for purchase..$^{10,12-20,22,24-27,37}$ 
Table 1: Crowding agents used for this study

\begin{tabular}{|c|c|c|c|}
\hline $\begin{array}{c}\text { Crowding } \\
\text { Agent }\end{array}$ & $\begin{array}{c}\text { Molecular Weight } \\
\text { (g/mol) }\end{array}$ & Vendor & $\begin{array}{c}\text { Lot } \\
\text { Number }\end{array}$ \\
\hline Dextran & 500,000 & Fisher Biotech & 025794 \\
\hline PEG & 20,000 & Fluka & $440987 / 1$ \\
\hline PVP & 40,000 & MP & R25781 \\
\hline Ficoll 70 & 70,000 & Sigma & $103 \mathrm{~K} 1533$ \\
\hline
\end{tabular}

\subsection{Solubility Studies}

The solubility of diketopiperazine (DKP) was analyzed by measuring changes in the density of crowded solutions to determine if the properties of bulk water are altered in the environment. The reason DKP is the model compound for solubility studies is because DKP has the same atom connectivity as the polypeptide backbone of a protein. Refer to Figure 9 for the structure of DKP and the polypeptide backbone of a protein.

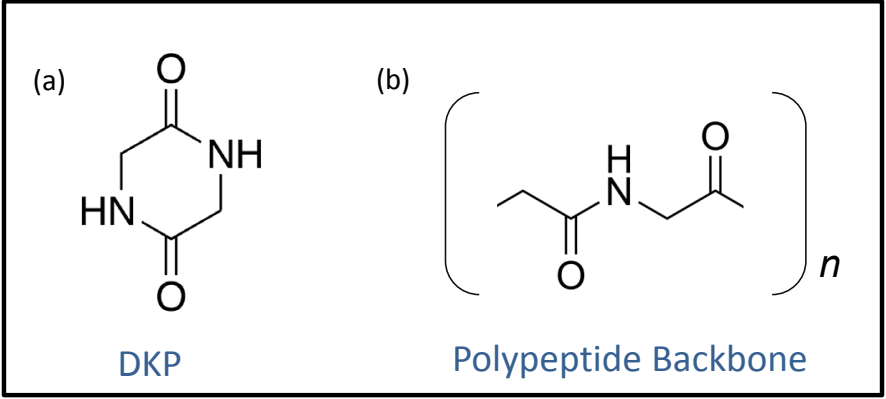

Figure 9: Comparison of DKP and polypeptide backbone. (a) Structure of diketopiperazine (DKP). (b) Structure of the polypeptide backbone of a protein.

For a typical experiment, different amounts of DKP were weighed (weight recorded), and $3.5 \mathrm{~mL}$ of one of the $10 \%$ crowding solutions was transferred into each of eight vials. The mass amounts of DKP were chosen based on achieving at least three sample vials below the saturation point, and three more sample vials above the saturation point. Also a control sample with only the crowding 
solution and no DKP was prepared. All sample vials were capped and incubated on a rotary mixer for a minimum of $48 \mathrm{~h}$ at a desired temperature before analysis. Density measurements were conducted at the same incubation temperature on a high-precision oscillating U-tube density meter (model DMA 5000, Anton Parr). Before analysis, the density meter was calibrated with ultra-pure water as per the manufacturer's specifications. Samples were injected into the inlet port of the density meter through a $0.22 \mu \mathrm{m}$ pore size filter, and the density value was measured. Solution density versus amount of DKP in each vial was plotted to determine DKP solubility. The three points before saturation were fitted with a linear trend line, and the three density value points after saturation were averaged. Then by inputting the averaged saturation density as the y-value into the linear equation, the saturation point or solubility point was determined. Each $10 \%$ crowding solution was performed in triplicate at each temperature level, except for $10 \%$ Ficoll 70 and $10 \%$ PEG at $50{ }^{\circ} \mathrm{C}$ which were performed in duplicate. Additionally, experiments with 25\% Dextran and 25\% PVP at each temperature level were performed in triplicate. The temperature levels were achieved by using incubators set at $25^{\circ} \mathrm{C}, 37^{\circ} \mathrm{C}$, and $50^{\circ} \mathrm{C}$. Refer to Figure 10 for a sample plot of results from a solubility study. Similar experiments have been conducted for different salts as a function of salt concentration. ${ }^{38}$ 


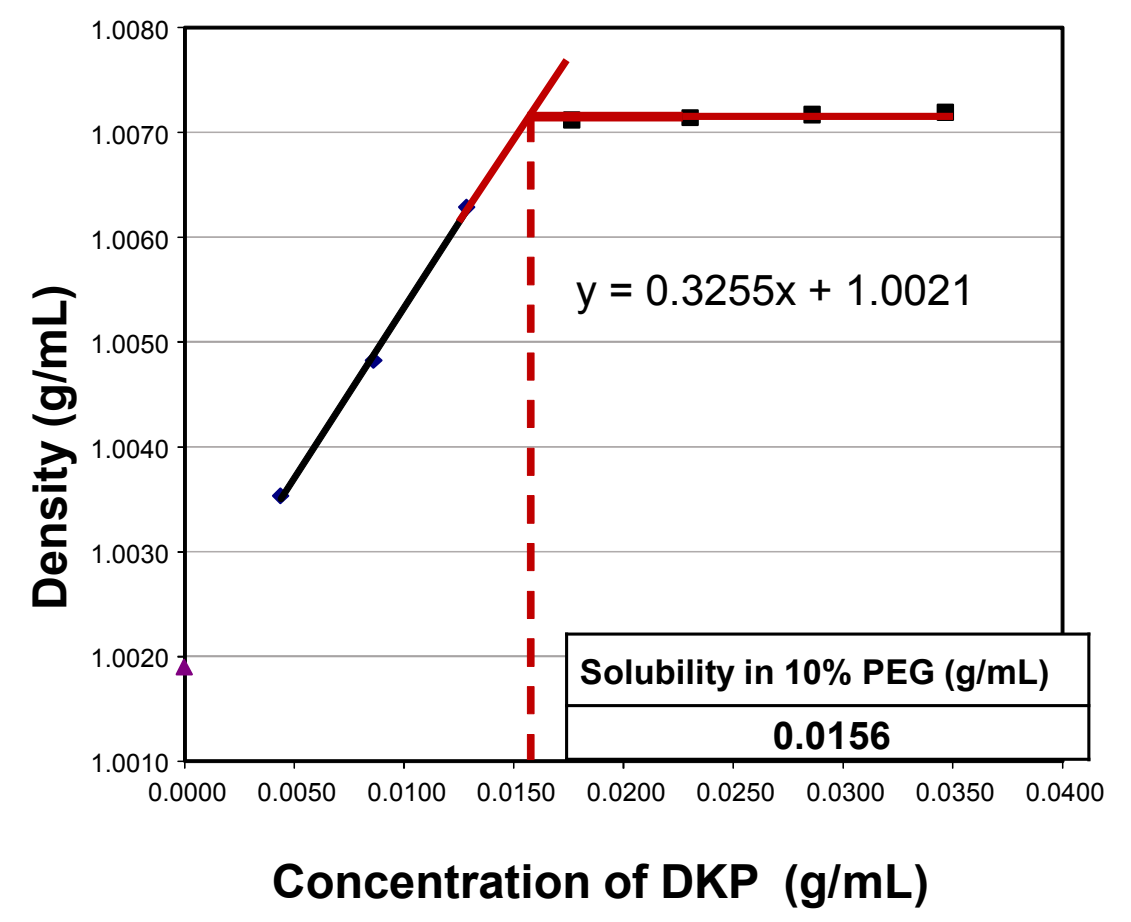

Figure 10: Example of a DKP solubility plot. This plot was charted as density versus concentration of DKP. As you can see, the first three samples (blue points) give a linear fit, while the last three samples (pink points) indicate that the solution is oversaturated. Using the $y=m x+b$ from the linear fit, the average of the last three samples is plugged into the linear trendline equation as the $y$ value to calculate out the $x$ value which is the intersection and solubility point of DKP in the crowded solution. The red dashed line shows the solubility point of DKP in $10 \%$ PEG to be 0.0156 .

The grams of water per milliliter of solution was determined by subtracting the known mass of crowding agent per unit volume from the solution density.

The density of the $10 \%$ crowding solution without the presence of DKP (control), was also measured during each trial. Since the solution consists of $10 \mathrm{wt} \%$ of the crowding agent, simply multiplying the density of the solution by $90 \%$ will yield the mass of water per volume of the crowding solution, and dividing the solubility point by this factor will give the solubility in milligrams of DKP per gram of water. 


\subsection{Binding Studies}

Binding experiments were performed using ethylenediaminetetraacetic acid (EDTA) and calcium chloride $\left(\mathrm{CaCl}_{2}\right)$ because high concentrations can be tested by isothermal titration calorimetry (ITC) without risk of precipitation, and because this binding reaction has been used to establish desolvation energies and the standard state free energy in the absence of crowding agents at various temperatures. ${ }^{35}$ Also, EDTA binds the calcium ion with an enthalpy ranging from $-12 \mathrm{kcal} \mathrm{mol}^{-1}$ to $+1.9 \mathrm{kcal} \mathrm{mol}^{-1}$, suggesting that solvent properties contribute to the enthalpy of binding. ${ }^{39}$ EDTA wraps around the calcium ion with its four carboxylic groups and two nitrogen groups to form a strong metal chelator.

Solutions of $10 \%$ Ficoll 70 or PVP were prepared at room temperature using $10 \mathrm{mM}$ MES buffer adjusted to $\mathrm{pH}$ 6.2. The reactants (EDTA or $\mathrm{CaCl}_{2}$ ) were prepared in stock concentrations of $50 \mathrm{mM}$ EDTA or $500 \mathrm{mM} \mathrm{CaCl}_{2}$ in MilliQ water. Each stock solution was added separately at different concentration levels to the $10 \mathrm{wt} \%$ polymer solution prior to $\mathrm{pH}$ adjustment. The $\mathrm{pH}$ adjustment to 6.2 is critical because the protonation state and binding properties of EDTA depend on the $\mathrm{pH}$. EDTA is sensitive to the buffer in which the process occurs and, at $\mathrm{pH}$ close to physiological conditions, EDTA behaves as a hexadentate unit and uses the deprotonated carboxylate groups and two nitrogen atoms (each has a pair of non-bonding electrons) to wrap itself around the calcium ion to arrange octahedrally. The formation of the EDTA: $\mathrm{Ca}^{2+}$ complex is triggered by the proton displacement from the nitrogen site which leads to more stability of the 
complex. When the four carboxyl groups and two amino groups from the EDTA are all deprotonated, then the chelator is at maximum affinity for $\mathrm{Ca}^{2+}$. The $\mathrm{pKa}$ values for the groups are $\mathrm{p} K_{1}=1.15, p K_{2}=1.15, p K_{3}=2.12, p K_{4}=2.57, p K_{5}=$ 6.16 , and $\mathrm{p} K_{6}=10.26 .{ }^{39}$ For the binding experiments the EDTA is not completely deprotonated, only five groups are deprotonated, based on the $\mathrm{pH}$ adjustment to 6.2. The reason all six groups of the EDTA were not deprotonated for the binding experiments was because the binding reaction would then go beyond the measuring range of the ITC. Having five groups of the EDTA deprotonated is more than sufficient for studying the binding of EDTA to $\mathrm{Ca}^{2+}$.

ITC is used for the binding experiments because this method is capable of accurately measuring the binding affinity $(K)$ along with directly measuring the enthalpy change $(\Delta \mathrm{H})$ of binding and the binding stoichiometry $(\mathrm{N}){ }^{40,41}$ ITC results are typically plotted as power versus time, where power is the energy needed to maintain constant temperature in the sample cell. A change in power (voltage) is detected because, as the $\mathrm{CaCl}_{2}$ is injected into the sample cell and binds to the EDTA, heat from the reaction is released or absorbed. The binding isotherm formed from the data is used to determine the binding affinity, along with the change in enthalpy per binding event, and the binding stoichiometry. The change in enthalpy is measured directly from the binding isotherm as the amount of heat released per mole of $\mathrm{Ca}^{2+}$ bound. The binding affinity is determined from the slope of the isotherm and the binding stoichiometry is from 
the binding ratio in the center of the isotherm. Refer to Figure 11 for a sample ITC plot.

The ITC instrument from Microcal (model VP-ITC) was used for analysis with the Origin Software. Before loading the sample cell of the ITC with EDTA in a $10 \%$ crowding solution, a 25 mM EDTA solution was placed in the sample cell for at least one hour to saturate any nonspecific binding sites. The 25 mM EDTA solution was removed from the cell, and then the cell was rinsed once with the desired EDTA solution in 10\% crowding agent and loaded with a degassed sample of the same solution. Degassing was achieved by placing an aliquot of the solution in a vacuum degasser (Thermovac) for a few minutes. Then a calcium chloride solution at 10 times the concentration of EDTA and in the same $10 \%$ crowding solution was loaded into the syringe. Depending on the concentration of EDTA and $\mathrm{CaCl}_{2}$, the analog input range, reference power, number of injections, and injection spacing were adjusted before the start of the run. Refer to Table 2 for exact instrument parameters used at each concentration level of EDTA and $\mathrm{CaCl}_{2}$. 


\section{Time $(\min )$}

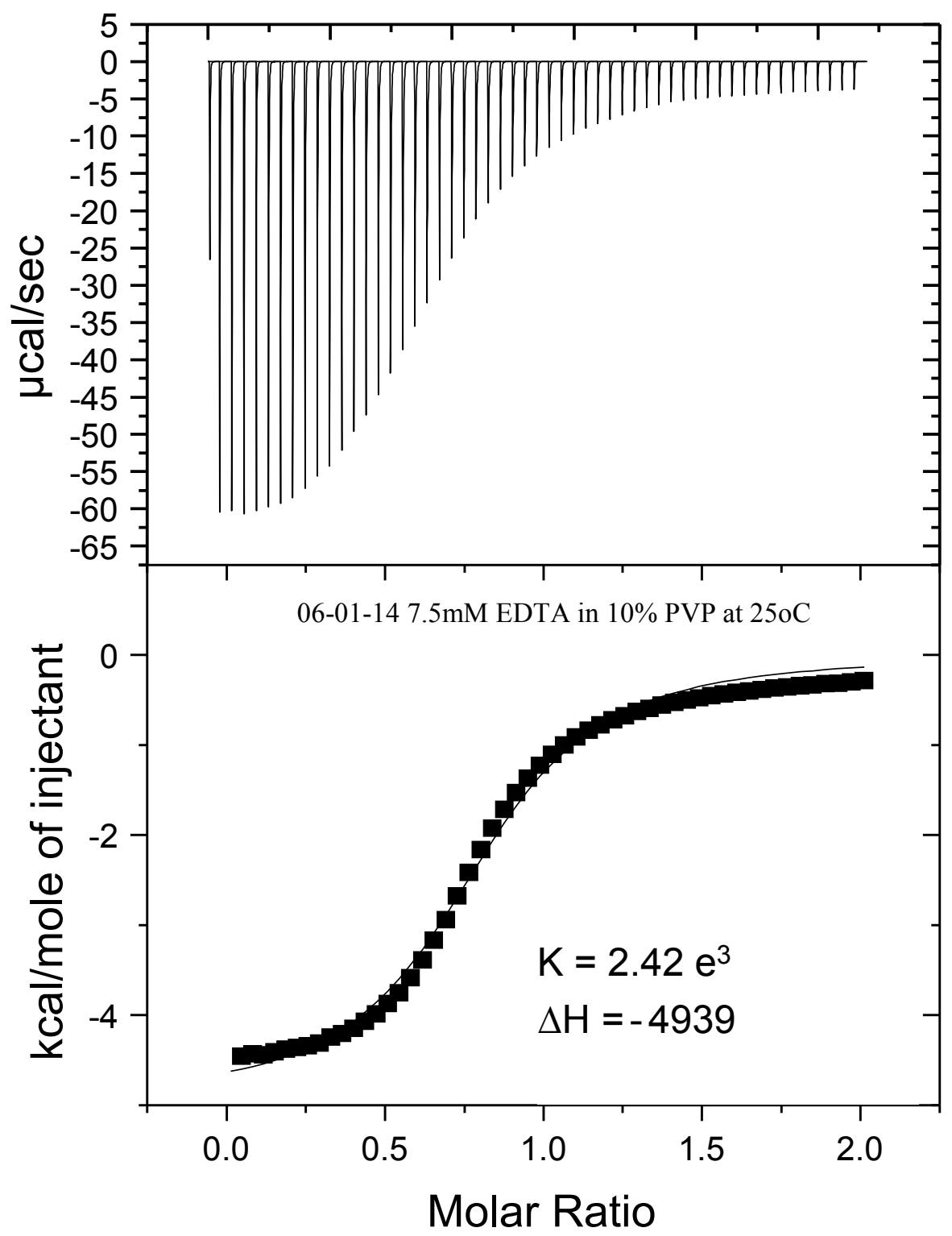

Figure 11: A sample ITC plot from an EDTA \& $\mathrm{CaCl}_{2}$ binding experiment in $10 \%$ PVP solution. The upper plot is the power change of each injection versus time, and the bottom plot is the curve generated from the raw data that determines the binding affinity and change in enthalpy. 
Table 2: EDTA \& $\mathrm{CaCl}_{2}$ concentrations with ITC instrument parameters

\begin{tabular}{|c|c|c|c|c|c|c|}
\hline $\begin{array}{c}\text { EDTA } \\
\text { Concentration } \\
(\mathrm{mM})\end{array}$ & $\begin{array}{c}\mathrm{CaCl}_{2} \\
\text { Concentration } \\
(\mathrm{mM})\end{array}$ & Temperature & $\begin{array}{l}\text { Analog } \\
\text { Input } \\
\text { Range } \\
\text { (volts) } \\
\end{array}$ & $\begin{array}{c}\text { Reference } \\
\text { Power } \\
\text { (volts) }\end{array}$ & $\begin{array}{c}\text { Number } \\
\text { of } \\
\text { injections }\end{array}$ & $\begin{array}{c}\text { Spacing } \\
\text { of } \\
\text { injections } \\
\text { (seconds) }\end{array}$ \\
\hline 0.500 & 5.00 & \multirow{4}{*}{$25^{\circ} \mathrm{C}$} & 1.25 & 30 & 54 & 240 \\
\hline 2.500 & 25.00 & & 1.25 & 30 & 54 & 500 \\
\hline 7.500 & 75.00 & & 5.00 & 60 & 54 & 500 \\
\hline 12.500 & 125.00 & & 10.00 & 90 & 107 & 600 \\
\hline
\end{tabular}

The first injection volume for all ITC runs was $2.5 \mu \mathrm{L}$ and was not included in the analysis because a small amount of sample was expected to be lost during the transfer of the syringe into the sample cell which led to an inaccurate dispensing of the first injection. ${ }^{42}$ Also as the syringe for the ITC purged and refilled itself with the solution before the start of the run, the plunger has to change screw direction making the first injection inaccurate due to a backlash error. ${ }^{42}$ This backlash error could cause an inaccurate estimation of the reaction stoichiometry, but the error was minimized by using the down syringe function on the control panel after the purging/refilling cycles and prior to the start of the run. ${ }^{42}$ The remaining injections for each analysis were set at $5.0 \mu \mathrm{L}$, except for the runs at the highest concentration in Table 2, for which all 107 injections were set a $2.5 \mu \mathrm{L}$. The reason $2.5 \mu \mathrm{L}$ injection volume was used and the number of injections was increased at the highest concentrations was to generate more data points for a better fit. If those conditions were not implemented than the injections would not have formed a smooth curve. After the ITC binding experiment, the analysis software allowed one to make a graph like Figure 12 , from which one determined the binding affinity value $\left(\mathrm{K}_{i}\right)$ and a binding enthalpy 
value $(\Delta \mathrm{H})$. As a control experiment, calcium chloride was injected into a $10 \%$ crowded solution in the absence of EDTA at each $\mathrm{CaCl}_{2}$ concentration level and subtracted from the corresponding binding data points prior to generating the curve. For the 10\% Ficoll 70 solution and 10\% PVP solution, each concentration level was analyzed in triplicate.

\subsection{Dilution Studies}

Dilution studies were done using the ITC to directly measure changes in the enthalpy of water. The $10 \%$ crowded solution was loaded into the sample cell, and pure Milli-Q water was loaded into the syringe. Then small $1 \mu \mathrm{L}$ volumes of water were injected repeatedly into the crowded solution. Refer to Figure 12 for a sample plot of the raw data obtained from a dilution experiment. The changes in enthalpy for the last three injections were averaged to give one data value for the ITC run. By studying the change in enthalpy for different types of crowded environments relative to neat water, one can compare the effect of each polymer on water. Each crowded solution was analyzed at each temperature level $\left(25^{\circ} \mathrm{C}, 37^{\circ} \mathrm{C}\right.$, and $\left.50^{\circ} \mathrm{C}\right)$ in triplicate. 


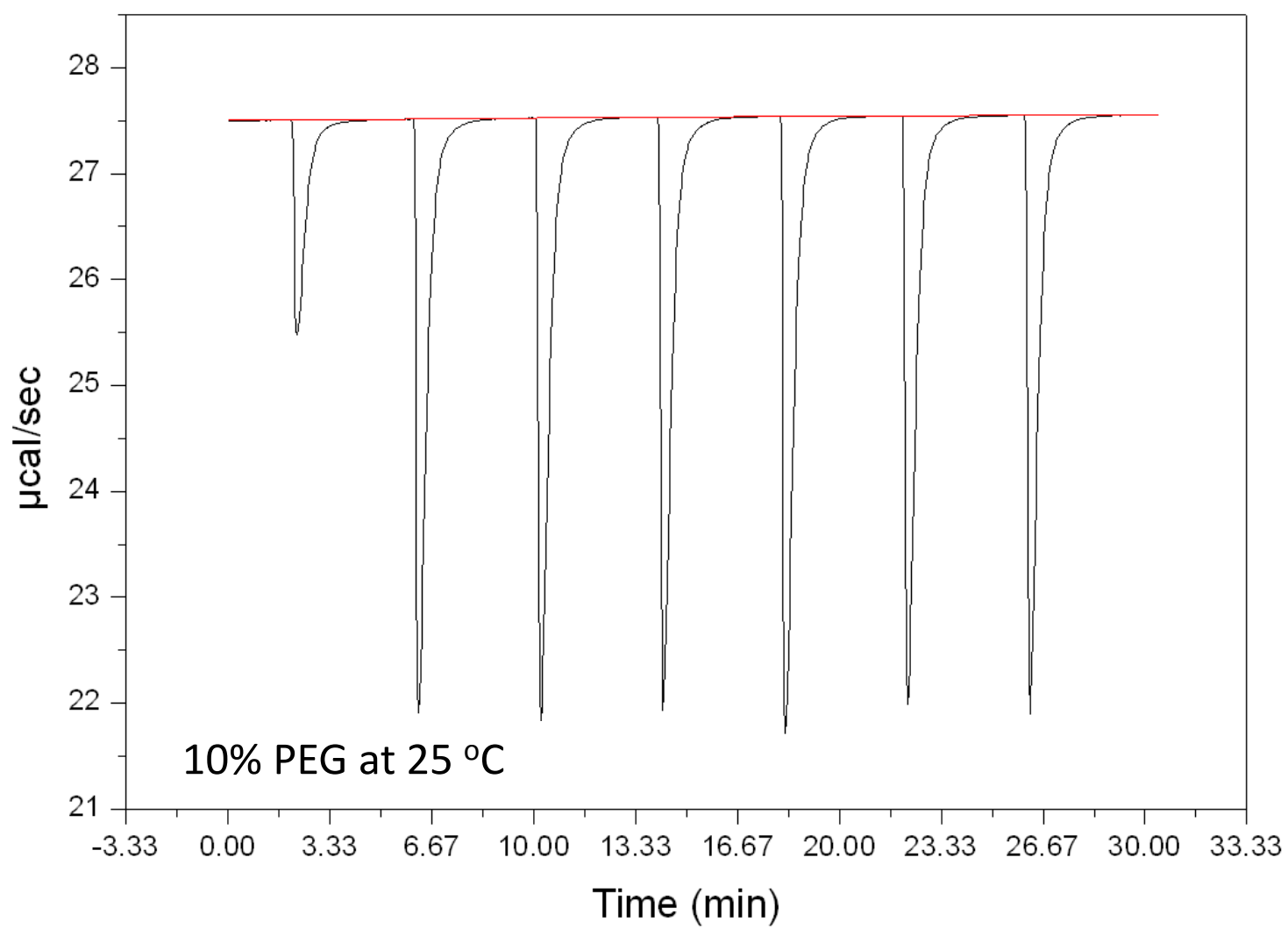

Figure 12: A sample ITC plot of water injection into a $10 \%$ PEG solution at $25{ }^{\circ} \mathrm{C}$. The first injection is ignored, and the last three injection enthalpies are averaged to obtain the change in enthalpy for one microliter of water. 


\section{CHAPTER 3}

\subsection{RESULTS AND DISCUSSION}

The purpose of the solubility studies, binding experiments, and dilution experiments is to understand how macromolecular crowding influences water. Dilute solutions are no longer sufficient to characterize protein conformation, function, and efficacy from experimentation, especially if one aims to understand protein function in a biological setting. Macromolecular crowding and the solvent (water properties) can have positive or negative influences on the reaction processes in the intracellular environment, whether the influence is by excluded volume effects, non-specific interactions, and/or changing the properties of the solvent. It is important that studies are performed to characterize crowding and solvent effects on reaction equilibria of biological relevance.

\subsection{Solubility Results}

The DKP solubility results are graphed in units of $\mathrm{mg} \cdot \mathrm{g}^{-1} \mathrm{H}_{2} \mathrm{O}$ in Figure 13. The control experiment is the solubility study conducted in dilute solution without the presence of a crowding agent. The results are converted to mg of DKP per gram of water so that the solubility values can be compared on the same solvent basis. These experiments are not measuring macromolecular crowding effects because crowding is studied typically by looking at excluded volume effects on large macromolecules, whereas DKP is a small molecule. This suits the needs for this experiment because the objective is to see how water is influenced by the crowding agent, not the influence of the crowding agent on the test molecule. 


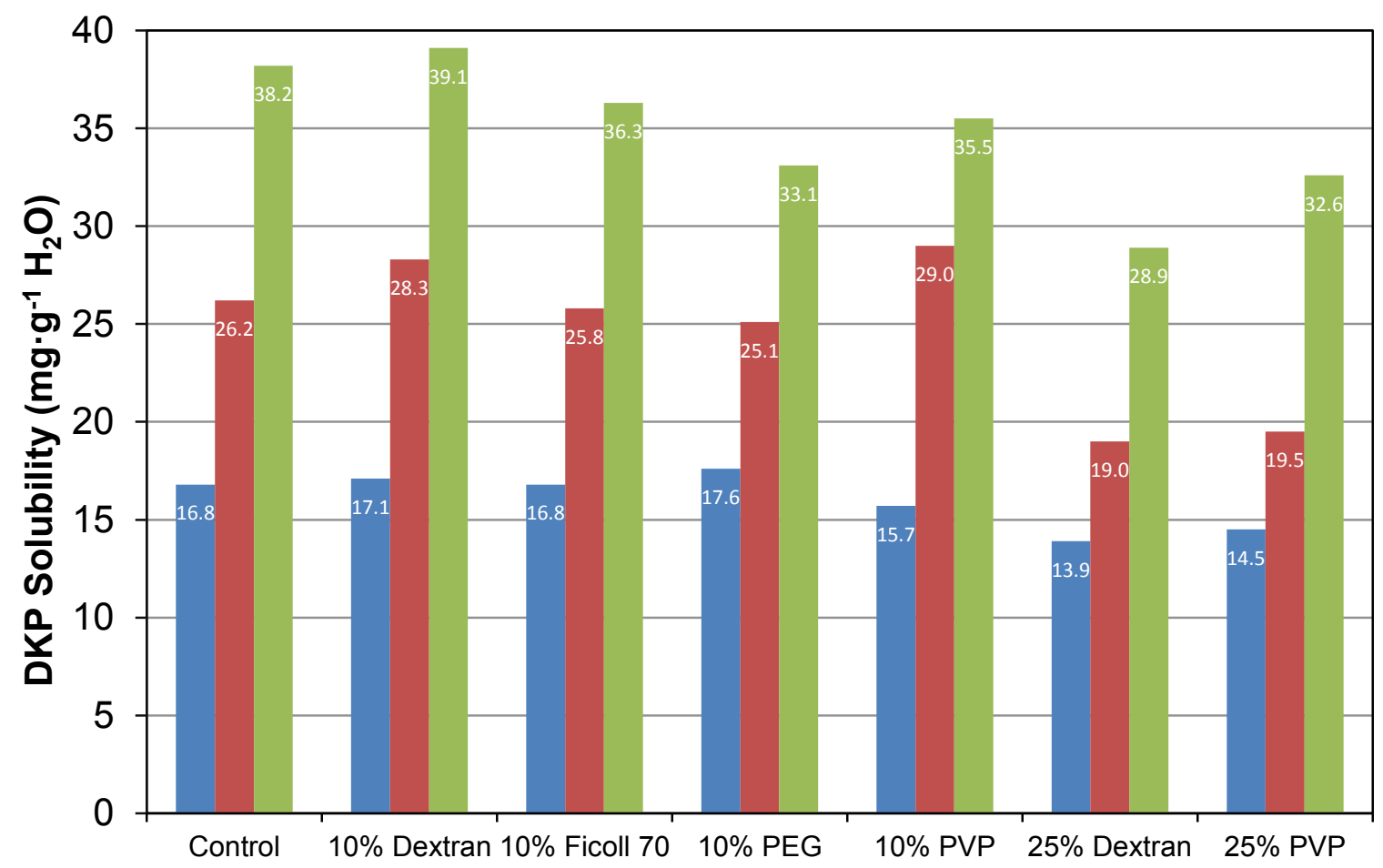

Crowding Solutions

$25^{\circ} \mathrm{C} \quad-37^{\circ} \mathrm{C} \quad 50^{\circ} \mathrm{C}$

Figure 13: DKP solubility $\left(\mathrm{mg} \cdot \mathrm{g}^{-1} \mathrm{H}_{2} \mathrm{O}\right)$ in various environments. Each grouping is a different experimental solution, and each bar is a different analysis temperature. The results for the control are taken from a publication report from the same laboratory using the same methods. ${ }^{38}$

If the solubility of DKP was higher in crowded solutions, then the crowding agent could be increasing the free energy of bulk water to enhance solubility. However, it was expected that higher concentrations of macromolecules should lower DKP solubility in comparison to the control solution if crowding agents also stabilize globular proteins due to decreases in the free energy of bulk water. Solubility increased with temperature at each condition, but that is typically 
observed for any compound. Comparing the solubility results of the crowded environments to the control environment, there are only minor differences in solubility. The $10 \%$ Dextran solution at $50^{\circ} \mathrm{C}$ had the highest solubility value, and the $25 \%$ Dextran solution at $25{ }^{\circ} \mathrm{C}$ had the lowest solubility value. The cases in which the solubility of DKP is higher than the control indicate an increase in the free energy of bulk water resulting in a more positive desolvation energy, and the cases in which the solubility of DKP is lower than the control indicate a decrease in the free energy of bulk water leading to a more negative desolvation energy. ${ }^{38}$ Overall, the results indicate that the selected polymers have only a minimal or modest influence on the bulk water properties; none of the DKP solubility results in the crowded environments are significantly higher or lower than the DKP solubility control results. Because DKP is used in this study to mimic the protein backbone, one would predict that these crowding agents should mediate their effects on protein folding through excluded volume effects and not by altering the average properties of the bulk water. The results graphed in Figure 13 are presented in detail in Appendix A and include the \% error of precision.

\subsection{Binding Results}

The binding results obtained from ITC analysis for the $\mathrm{Ca}^{2+}$ :EDTA complex at the various concentrations in the macromolecular crowded solutions of $10 \%$ Ficoll 70 and $10 \%$ PVP are summarized in Figure 14 and tabulated in Appendix B. Using Equation 3 from the desolvation model and plotting the value of $-\mathrm{RT} \ln \mathrm{K}_{i}$ versus the concentration of the complex at equilibrium, a linear fit should be 
apparent if the model holds for these crowded nonideal systems. A single point for the $10 \%$ Dextran solution at the lowest concentration level of the $\mathrm{Ca}^{2+}$ :EDTA complex is also plotted in Figure 14. The results indicate that the equilibrium ratio $\left(\mathrm{K}_{i}\right)$ is not a constant as a function of the $\mathrm{Ca}^{2+}$ :EDTA concentration, refer to Table 3. The $10 \%$ Dextran solution was not analyzed at higher concentrations because, when looking at the 10\% Ficoll solution and 10\% PVP solution results, linearity was not observed like the control results, so this aspect of the project was halted.

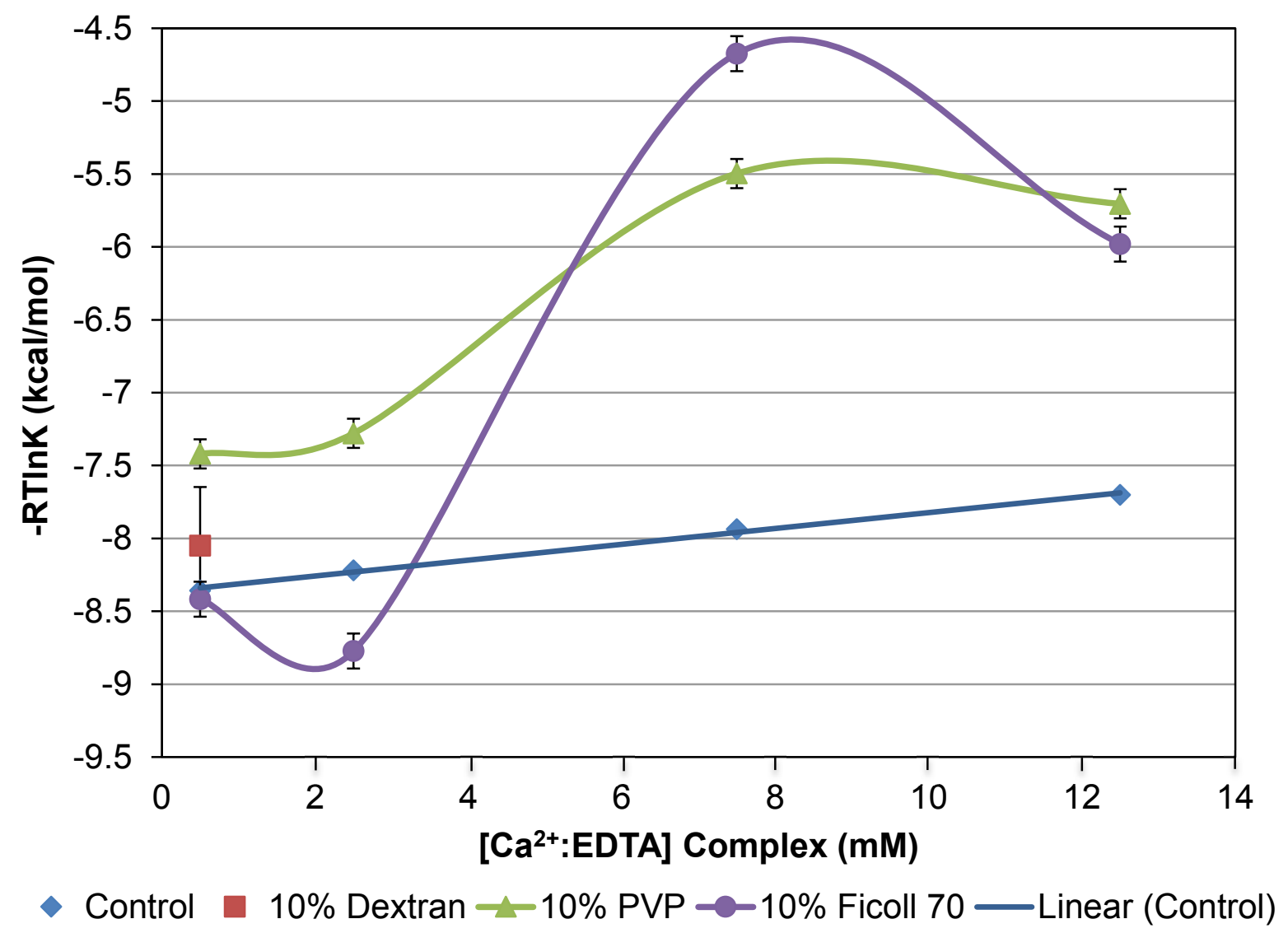

Figure 14: Plot of $-\mathrm{RTInK}$ iversus concentration of $\mathrm{Ca}^{2+}$ :EDTA complex. Each line color represents a different solution. The control results are the binding in solution without the presence of crowding agent, as obtained from a previous publication. ${ }^{35}$ 
Table 3: Binding Equilibria (K) Results

\begin{tabular}{|c|c|c|c|c|c|c|c|c|c|c|c|c|}
\hline \multirow{2}{*}{$\begin{array}{c}{\left[\mathrm{Ca}^{2+}: \text { EDTA] }\right.} \\
\text { Complex }\end{array}$} & & $\begin{array}{c}\text { Control }^{1} \\
\text { Average }\end{array}$ & & $10 \%$ & $\begin{array}{r}\% \text { Ficoll } 7 \\
\text { Average }\end{array}$ & & & $\begin{array}{l}\text { 10\% PVP } \\
\text { Average }\end{array}$ & & & $\begin{array}{l}\text { 0\% Dextr } \\
\text { Average }\end{array}$ & \\
\hline & $K \times 10^{5}$ & Error of $\mathrm{K}$ & -RTInK & $\mathrm{K} \times 10^{5}$ & Error of $\mathrm{K}$ & -RTInK & $K \times 10^{5}$ & Error of $\mathbf{K}$ & $-R T \ln K$ & $K \times 10^{5}$ & Error of $\mathrm{K}$ & $-R T \operatorname{lnK}$ \\
\hline 0.5 & 13.4 & 0.30 & -3.63 & 14.8 & 0.03 & -8.42 & 2.75 & 0.10 & -7.42 & 7.98 & 0.62 & -8.05 \\
\hline 2.5 & 10.6 & 0.30 & -3.57 & 27.0 & 0.12 & -8.77 & 2.17 & 0.04 & -7.28 & & & \\
\hline 7.5 & 6.58 & 0.29 & -3.45 & 0.0267 & 0.08 & -4.67 & 1.07 & 0.07 & -5.50 & & & \\
\hline 12.5 & 4.48 & 0.14 & -3.35 & 0.242 & 0.03 & -5.98 & 1.52 & 0.1 & -5.70 & & & \\
\hline
\end{tabular}

${ }^{1}$ Control results were obtained from published results analyzed in the same laboratory. ${ }^{35}$

The binding results depicted in Figure 14 using the crowding agents as a secondary solute do not yield a linear trend, so the standard state Gibbs free energy or desolvation energy cannot be calculated from Equation 3. The results are not consistent with the desolvation energy model, or with the linear trend observed in the control solution. Most surprising is the observation that EDTA and $\mathrm{Ca}^{2+}$ binding affinity increased slightly in $10 \%$ Ficoll relative to the control but diminished in a non-linear fashion as the concentrations of EDTA and $\mathrm{Ca}^{2+}$ increased (Figure 14).

There are multiple reasons as to why the quantitative results obtained from the binding experiments are not consistent with the desolvation model. EDTA and $\mathrm{CaCl}_{2}$ interactions are sensitive to $\mathrm{pH}$, and the $\mathrm{pH}$ was not monitored after mixing stock $\mathrm{CaCl}_{2}$ and EDTA with the crowded solution during preparation, or after the binding experiment. Also, the initial measurements of $\mathrm{pH}$ of the reactant solutions in the crowded environment might not be accurate because the $\mathrm{pH}$ probe is not designed to measure $\mathrm{pH}$ for viscous nonideal solutions. Since the binding reactants are in a viscous solution with the crowding agent, the volume of 
each ITC injection might not be precise which would influence the binding curve and calculated fit. Another possibility could be that EDTA and/or $\mathrm{CaCl}_{2}$ are interacting with the crowding agent which was not taken into account in derivation of Equation 3.

Regarding the properties of water in the crowded solutions of the EDTA and $\mathrm{Ca}^{2+}$ model, the non-linear results were not anticipated, and further experiments are needed to confirm and understand this observation.

\subsection{Dilution Experiments}

The change in enthalpy results $(\Delta \mathrm{H})$ for water injected into the various crowded solutions of $10 \%$ polymer are presented in Figure 15 and Appendix C.

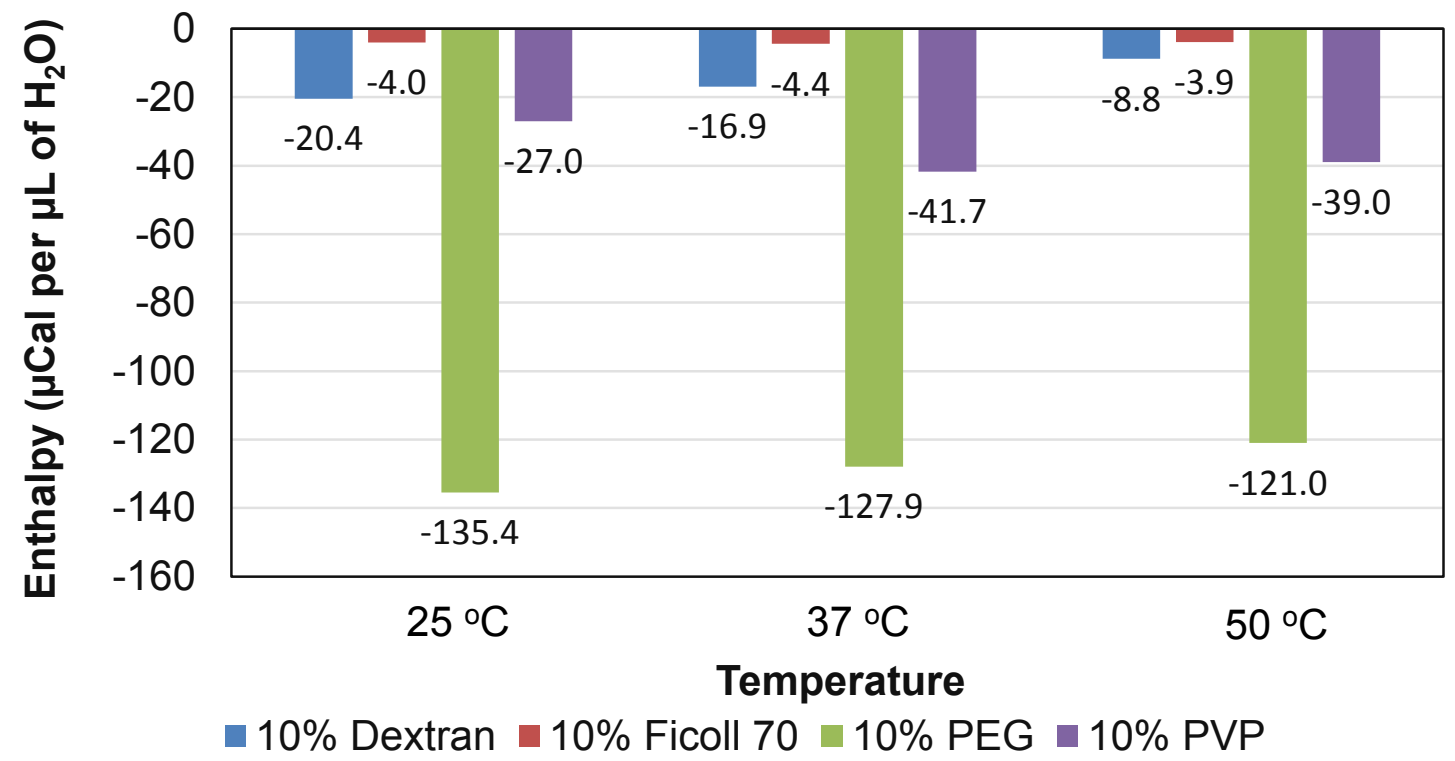

Figure 15: Graph of change in enthalpy $(\Delta \mathrm{H})$ of water in various crowded solutions versus temperature. Each bar color represents a different crowding agent, and the bar result is obtained from triplicate runs of each crowding solution at all three temperatures. Refer to Appendix A for detailed data with average error of each triplicate. 
The changes in enthalpy are all negative in Figure 15, which means that the neat water entering the sample cell is at a more favorable enthalpy (more negative) than the water in contact with the crowding agent. The magnitude of the enthalpy values from the crowded solutions of Dextran, Ficoll 70, and PEG are negligible in comparison to dilution experiments conducted in concentrated salt solutions by other members of the same laboratory (data not shown). These results are consistent with the DKP solubility experiments because the small enthalpy values suggest that the crowding agents have very little effect on the bulk properties of water. However, the point should be noted that this experiment does not reveal the change in entropy of water, a parameter which could also affect reaction equilibria. Interestingly, PEG yielded a more negative change in enthalpy in comparison to the other crowding agents, and this is consistent with literature observations that PEG might have more than an excluded volume effect on protein conformation. ${ }^{10,23}$ The change in enthalpy values would be useful for thermodynamic analyses where the desolvation energy for model reactions in the same solution are known from other experiments. Unfortunately, no desolvation energy values were obtained for any studies reported here.

\subsection{Conclusion}

Studying the effects of macromolecular crowding is crucial to understanding protein conformation equilibria and other reactions in the intracellular environment. ${ }^{3}$ Contributions of the solvent, such as the desolvation energy, should be part of the equations that describe reaction equilibria to provide a more 
in-depth understanding of the driving forces that shift the equilibria. ${ }^{34}$ The objective of this investigation is to study the influence of macromolecular crowding on water, by using the polymers Dextran, Ficoll, PEG, and PVP to mimic the crowded environment.

The solubility studies indicated that crowded solutions do not significantly influence the measured solubility of DKP in comparison to the solubility of DKP in a non-crowded solution, even following an increase in crowding from $10 \%$ to $25 \%$ by weight of Dextran and PVP (Figure 13). This could indicate that the crowding agents are indeed inert with regard to their solvent interactions. Yet the crowding agents have not been completely characterized because the experimental concentrations did not reach the level of crowding in a cellular environment (30$40 \%$ by weight).

The quantitative results collected from the binding experiments are not consistent with the desolvation energy model, and there can be numerous possibilities for the inconsistency. The binding affinity of EDTA to $\mathrm{Ca}^{2+}$ is very sensitive to $\mathrm{pH}$, and there is the possibility that the $\mathrm{pH}$ could have been altered during sample preparation. There is also the possibility that the viscosity of the solutions lead to inaccuracies during injections by the ITC. Even at $10 \%$ by weight crowding agent, the buffer is quite viscous, causing difficulty to observe crowding effects on the desolvation energy at physiological conditions using the ITC approach. 
The results from the dilution studies indicate that water enthalpy could be slightly more unfavorable in the presence of a crowding agent (more positive), but further analyses cannot be made without obtaining a desolvation energy for a model reaction in the same solution. This study does not reveal how the crowding agents will affect the thermodynamic properties of water when the concentration is closer to physiological conditions (30-40\% by weight).

Overall, the quantitative results suggest that the selected crowding agents are not having a large effect on bulk water properties. Thus, one must conclude that the reported effects of these crowding reagents in other studies is primarily

due to excluded volume effects. There is a difficulty to conduct experiments with crowding agent concentrations close to physiological conditions because of the increased viscosity and associated instrument limitations.

\subsection{Future Studies}

There are multiple opportunities for improving on the experimental methods employed here to gain a better understanding of the properties of water in a crowded environment.

For solubility and dilution studies, experiments might be beneficial to try to use $30 \%-40 \%$ polymer solutions to better mimic the higher amount of crowding inside the cell. As stated earlier, this could be a challenge because a higher percentage of crowding agent will be more viscous and difficult to degas and inject into the calorimeter or density meter for analysis. 
For the EDTA with $\mathrm{Ca}^{2+}$ binding experiments, the sample preparation and experimental parameters of the calorimetric method may need to be adjusted. The $\mathrm{pH}$ of the reactants should be monitored and adjusted as needed before ITC analysis. There is the possibility that a higher buffer concentration is required for the crowded solutions. In order to improve ITC injection precision of the viscous solutions, $10 \mu \mathrm{L}$ injections instead of $5 \mu \mathrm{L}$ might be beneficial. The larger injection volume could be tested to see if the results cause a change in the $\mathrm{K}$ value. Another possibility would be to use a $5 \%$ crowding agent solution instead of a $10 \%$ crowding agent to see if a more linear binding trend is observed with increasing reactant concentration. Another strategy would be to perform the binding experiment with the crowded solutions at a higher temperature $\left(37^{\circ} \mathrm{C}\right.$ and $50^{\circ} \mathrm{C}$ ) to see if the trend changes; a more linear trend at higher temperatures could be related to a reduced viscosity.

For all of these studies, only polymer crowding agents were used to mimic the crowded environment. Protein crowders such as BSA could also be used to study the influences on water, especially since they might be more physiologically relevant. There are challenges in working with protein crowding agents, however, because of their lack of stability at higher temperatures, propensity to aggregate, and the increased cost of the reagent.

Experiments with a mixed crowding solution that contains the presence of all four crowding agents might be interesting to perform. A previous publication 
indicated significantly better stability of the nucleotide hybrid during PCR with a mixture of crowding agents instead of a single crowding agent. ${ }^{13}$

In one publication, a hypothesis is proposed that crowding agents all act similarly on the stability of a test protein and that the entropic component favors the folded state, whereas the enthalpic component favors the unfolded state of the model protein. ${ }^{37}$ This supports the concept that there is a temperature dependency on crowding effects. The study has shown that each crowding agent, PVP, Ficoll, lysozyme, and BSA (all crowding agents prepared and analyzed at $100 \mathrm{~g} / \mathrm{L}$ ), has a cross-over temperature for which the temperature destabilized the folding of ubiquitin below the cross-over temperature and stabilized ubiquitin above the cross-over temperature ${ }^{37}$. The reported cross-over temperature is $48^{\circ} \mathrm{C}$ for PVP, $28^{\circ} \mathrm{C}$ for Ficoll, $24^{\circ} \mathrm{C}$ for lysozyme, and $37^{\circ} \mathrm{C}$ for BSA. ${ }^{37}$ Solubility, binding and dilution experiments conducted below, at, and above the cross-over temperature for Ficoll and PVP, to see if there is a detectable change in the properties of water, would be interesting and would help to explain this behavior. 


\section{REFERENCES}

1. Zhou, H.; Rivas, G.; Minton, A.P. Macromolecular crowding and confinement: Biochemical, biophysical, and potential physiological consequences. Annu. Rev. Biophys. 2008, 37, 375-397.

2. Ellis, R.J. Macromolecular crowding: An important but neglected aspect of the intracellular environment. Curr. Opin. Struct. Biol. 2001, 11, 114-119.

3. Arnaud, C.H. Close quarters: Crowded conditions such as those in cells can affect proteins' structure, function, and activity. Chem. Eng. News 2010, 88, 9-13.

4. Zimmerman, S.B.; Minton, A.P. Macromolecular crowding: Biochemical, biophysical, and physiological consequences. Annu. Rev. Biophys. Biomol. Struct. 1993, 22, 27-65.

5. Minton, A.P. The influence of macromolecular crowding and macromolecular confinement on biochemical reactions in physiological media. J. Biol. Chem. 2001, 276, 10577-10580.

6. Ellis, R.J.; Minton, A.P. Cell biology: Join the crowd. Nature 2003, 425, $27-$ 28.

7. Ellis, R.J. Macromolecular crowding: Obvious but underappreciated. Trends Biochem. Sci. 2001, 26, 597-604.

8. Minton, A.P. Implications of macromolecular crowding for protein assembly. Curr. Opin. Struct. Biol. 2000, 10, 34-39.

9. Minton, A.P. Models for excluded volume interaction between an unfolded protein and rigid macromolecular cosolutes: Macromolecular crowding and protein stability revisited. Biophys. J. 2005, 88, 971-985.

10. Zhang, D.; Wu, L.; Chen, J.; Liang, Y. Effects of macromolecular crowding on the structure and stability of human a-lactalbumin. Acta Biochim. Biophys. Sin. 2012, 44, 703-711. 
11. Haaf, F.; Sannar, A.; Straub, F. Polymers of N-vinylpyrrolidone: Synthesis, characterization and uses. Polym. J. 1985, 17, 143-152.

12. van den Berg, B.; Wain, R.; Dobson, C.M.; Ellis, R.J. Macromolecular crowding perturbs protein refolding kinetics: Implication for folding inside the cell. EMBO J. 2000, 19, 3870-3875.

13. Harve, K.S.; Lareu, R.; Rajagopalan, R.; Raghunath, M. Understanding how the crowded interior of cells stabilizes DNA/DNA and DNA/RNA hybrids-in silico prediction and in vitro evidence. Nucleic Acids Res. 2009, 38, 172-181.

14. Vöpel, T.; Makhatadze, G.I. Enzyme activity in the crowded milieu. PLoS ONE 2012, 7, 1-6.

15. van den Berg, B.; Ellis, R.J.; Dobson, C.M. Effects of macromolecular crowding on protein folding and aggregation. EMBO J. 1999, 18, 69272933.

16. Sasahara, K.; McPhie, P.; Minton, A.P. Effect of Dextran on protein stability and conformation attributed to macromolecular crowding. J. Mol. Biol. 2003, 326, 1227-1237.

17. Tokuriki, N.; Kinjo, M.; Negi, S.; Hoshino, M.; Goto, Y.; Urabe, I.; Yomo, T. Protein folding by the effects of macromolecular crowding. Protein Sci. 2004, 13, 125-133.

18. Batra, J.; Xu, K.; Qin, S.; Zhou, H. Effect on macromolecular crowding on protein binding stability: Modest stabilization and significant biological consequences. Biophys. J. 2009, 97, 906-911.

19. Zhou, Z.; Fan, J.; Zhu, H.; Shewmaker, F.; Yan, X.; Chen, X.; Chen, J.; Xiao, G.; Guo, L.; Liang, Yi. Crowded cell-like environment accelerates the nucleation step on amyloidogenic protein misfolding. J. Biol. Chem. 2009, 284, 30148-30158. 
20. Hatters, D.M.; Minton, A.P.; Howlett, G.J. Macromolecular crowding accelerates amyloid formation by human apolipoprotein C-II. J. Biol. Chem. 2002, 277, 7824-7830.

21. McNulty, B.C.; Young, G.B.; Pielak, G.J.; Macromolecular crowding in the Escherichia coli periplasm maintains a-synuclein disorder. J. Mol. Biol. 2006, 355, 893-897.

22. Munishkina, L.A.; Cooper, E.M.; Uversky, V.N.; Fink, A.L. The effect of macromolecular crowding on protein aggregation and amyloid fibril formation. J. Mol. Recognit. 2004, 17, 456-464.

23. Rivas, G.; Ferrone, F.; Herzfeld, J. Life in a crowded world. EMBO Rep. 2004, 5, 23-27.

24. Miklos, A.C.; Li, C.; Sharaf, N.G.; Pielak, G.J. Volume exclusion and soft interaction effects on protein stability under crowded conditions. Biochemistry 2010, 49, 6984-6991.

25. Miklos, A.C.; Sarkar, M.; Wang, Y.; Pielak, G.J. Protein crowding tunes protein stability. J. Am. Chem. Soc. 2011, 133, 7166-7120.

26. Wang, Y.; Sarkar, M.; Smith, A.E.; Krois, A.S.; Pielak, G.J. Macromolecular crowding and protein stability. J. Am. Chem. Soc. 2012, 134, 16614-16618.

27. Breydo, L.; Reddy, K.D.; Pial, A.; Felli, I.C.; Pierattelli, R.; Uversky, V.N. The crowd you're in with: Effects of different types of crowding agents on protein aggregation. Biochim. Biophys. Acta 2014, 1844, 346-357.

28. Phillip, Y.; Schreiber, G. Formation of protein complexes in crowded environments - from in vitro to in vivo. FEBS Lett. 2013, 587, 1046-1052.

29. Minton, A.P. Macromolecular crowding. Curr. Biol. 2006, 16, R269-R271.

30. Ball, P. Water as an active constituent in cell biology. Chem. Rev. 2008, 108, 74-108. 
31. Chaplin, M. Do we underestimate the importance of water in cell biology? Nat. Rev. Mol. Cell Biol. 2006, 7, 861-866.

32. Bianco, V.; Iskrov, S.; Franzese, G. Understanding the role of hydrogen bonds in water dynamics and protein stability. J. Biol. Phys. 2012, 38, 2748.

33. Berg, O.S. The influence of macromolecular crowding on thermodynamic activity: Solubility and dimerization constants for spherical and dumbbellshaped molecules in a hard-sphere mixture. Biopolymers 1990, 30, 10271037.

34. Eggers, D.K.; A bulk water-dependent desolvation energy model for analyzing the effects of secondary solutes in biological equilibria. Biochemistry 2011, 50, 2004-2012.

35. Castellano, B.M.; Eggers, D.K. Experimental support for a desolvation energy term in governing equations for binding equilibria. J. Phys. Chem. B 2013, 117, 8180-8188.

36. Minton, A.P. Influence of macromolecular crowding upon the stability and state of association of proteins: Predictions and observations. J. Pharm. Sci. 2005, 94, 1668-1675.

37. Zhou, H. Polymer crowders and protein crowders act similarly on protein folding stability. FEBS Lett. 2013, 587, 394-397.

38. Payumo, A.Y.; Huijon, R.M.; Mansfield, D.D.; Belk, L.M.; Bui, A.K.; Knight, A.E.; Eggers, D.K. Changes in apparent molar water volume and DKP solubility yield insights on the Hofmeister effect. J. Phys. Chem. B 2011, 115, 14784-14788.

39. Griko, Y.V. Energetics of $\mathrm{Ca}^{2+}$-EDTA interactions: Calorimetric study. Biophys. Chem. 1999, 79, 117-127.

40. Leavitt, S.; Freire, E. Direct measurement of protein binding energetics by isothermal titration calorimetry. Curr. Opin. Struct. Biol. 2001, 11, 560-566. 
41. Holdgate, G.A.; Ward, W.H.J. Measurements of binding thermodynamics in drug discovery. Drug Discov. Today 2005, 10, 1543-1550.

42. Mizoue, L.S.; Tellinghuisen, J. The role of backlast in the "first injection anomaly" in isothermal titration calorimetry. Anal. Biochem. 2004, 326, 125-127. 


\section{APPENDICES}

\section{Appendix A. Solubility Results and Representative Raw Data}

\section{Solubility Results}

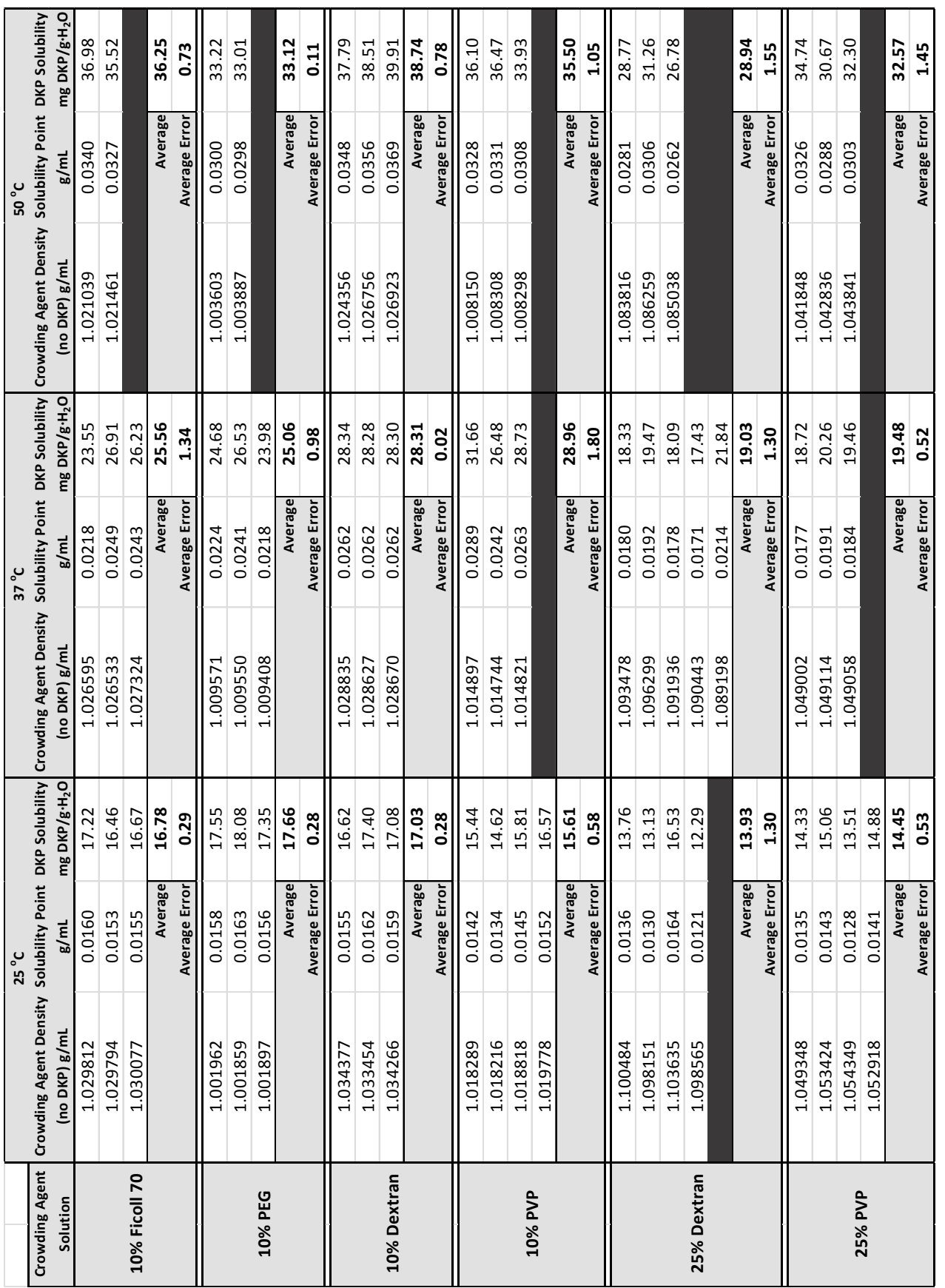




\section{0\% Ficoll 70 Representative Data}

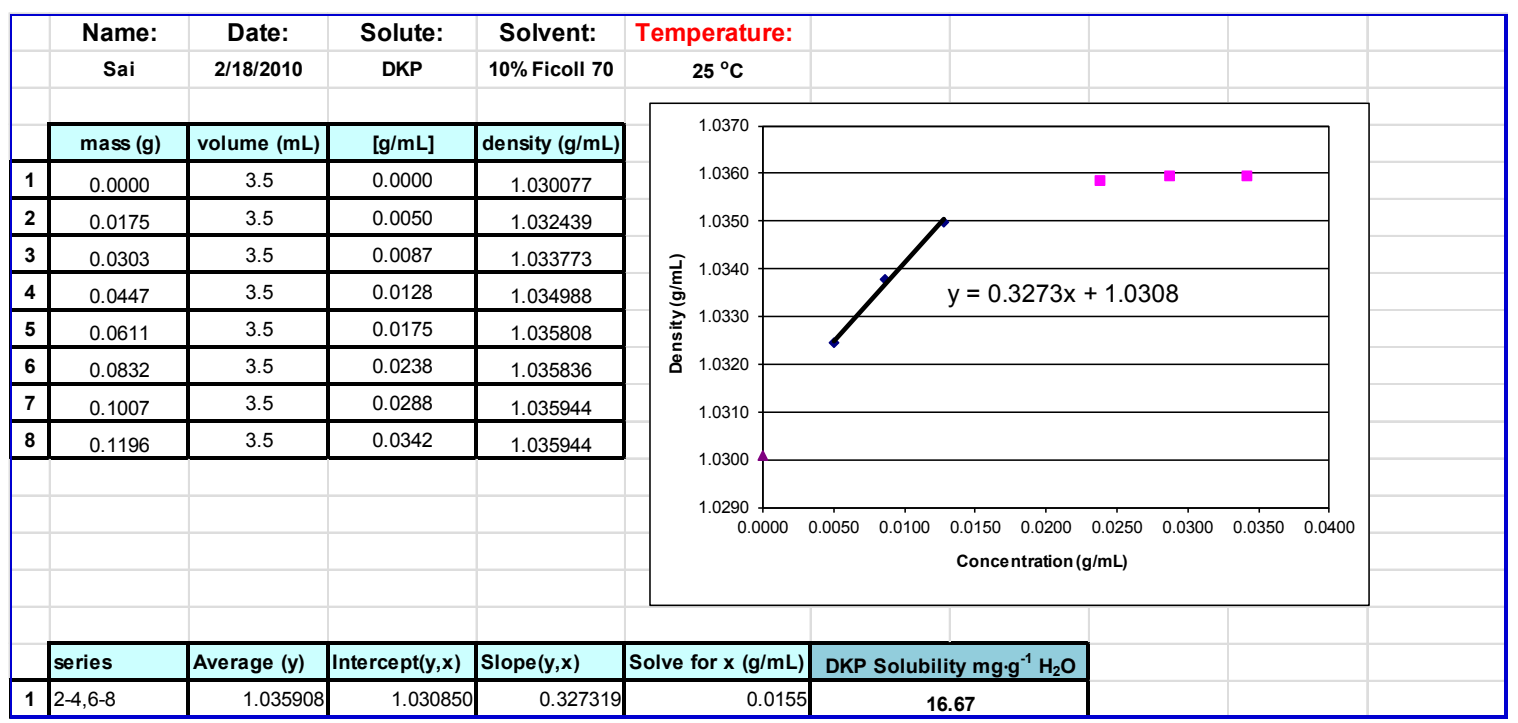

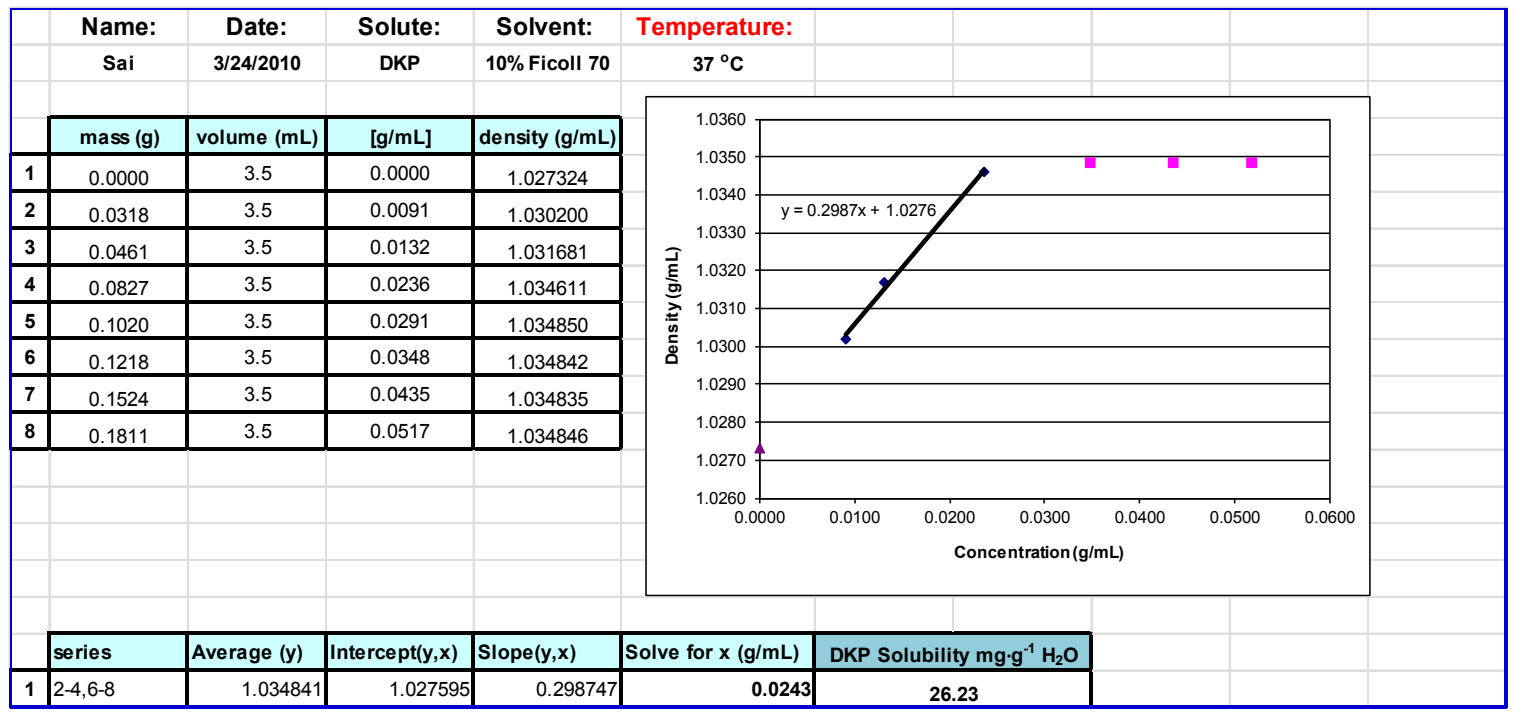




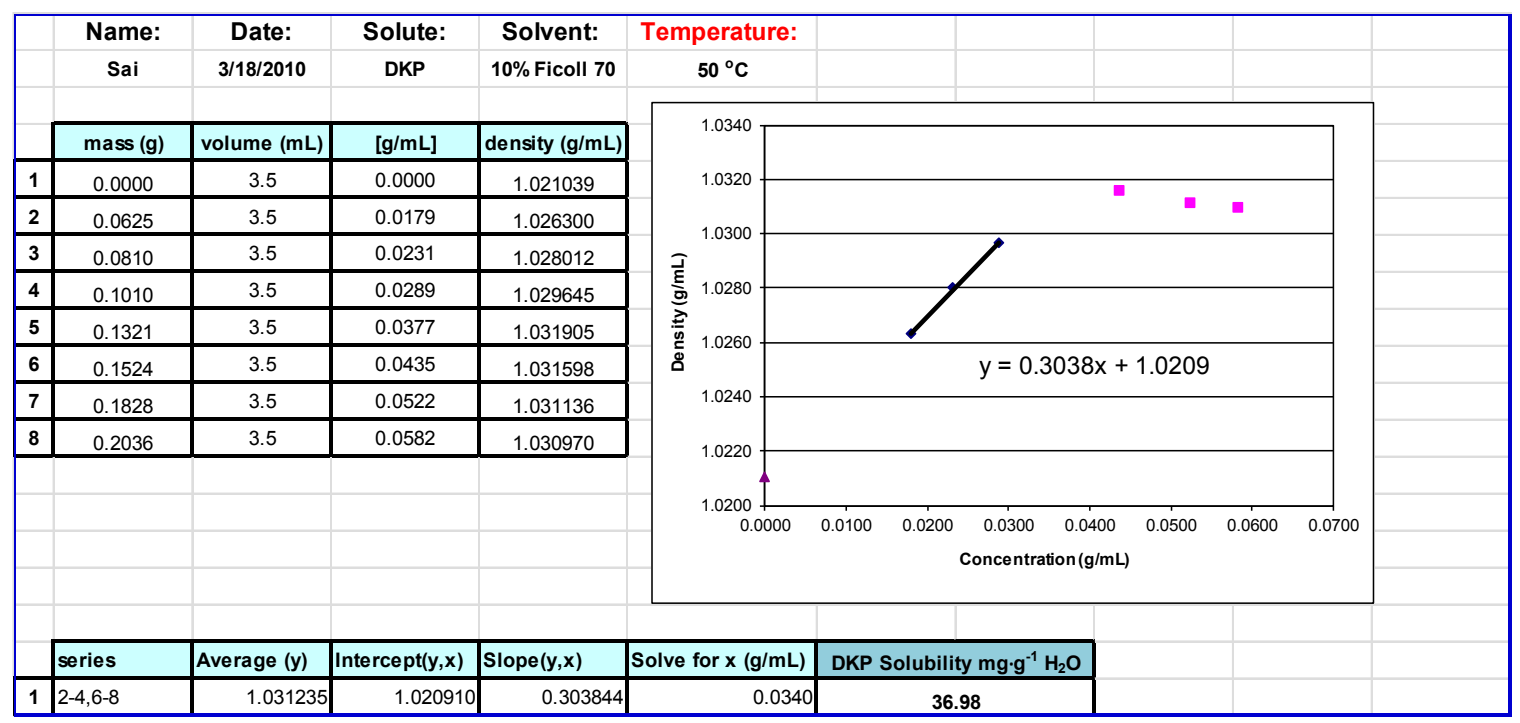

\section{0\% PEG Representative Data}

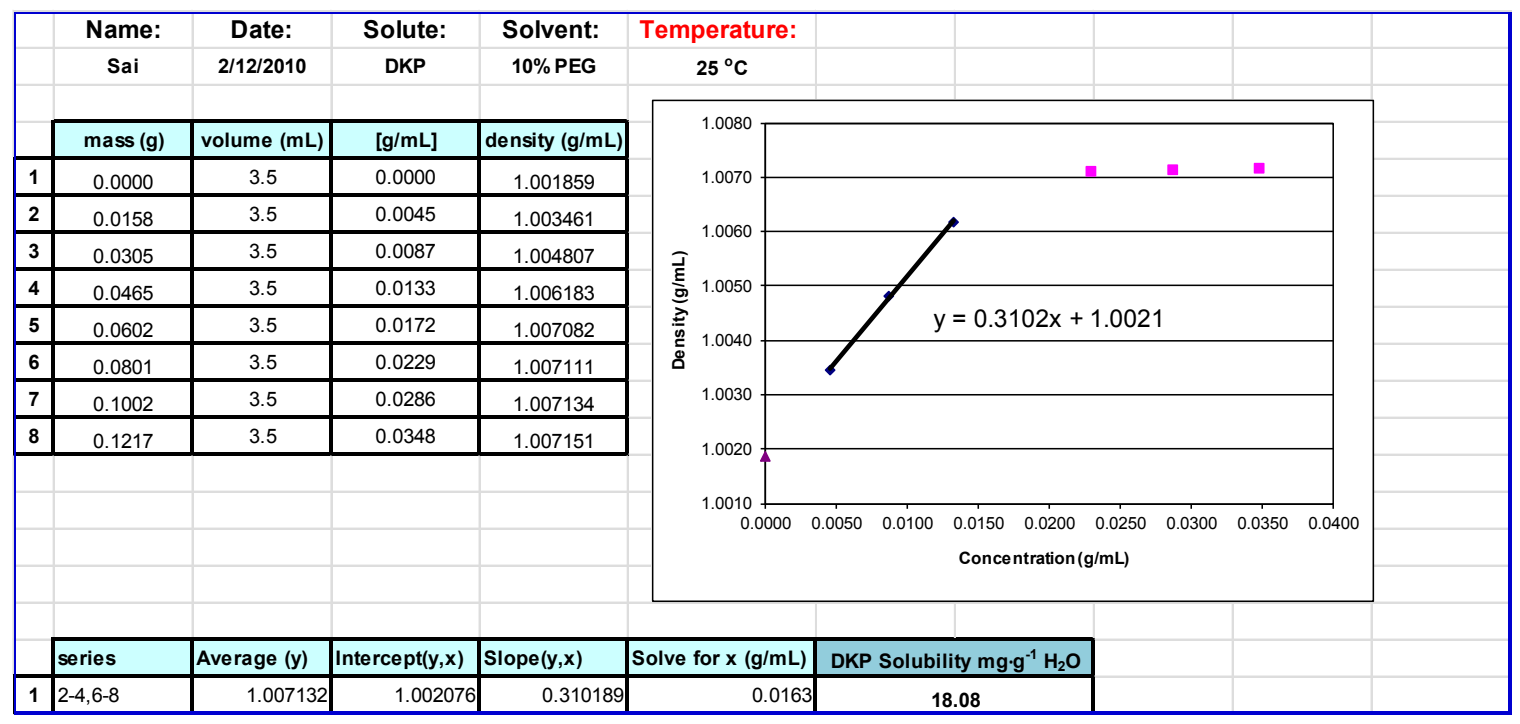




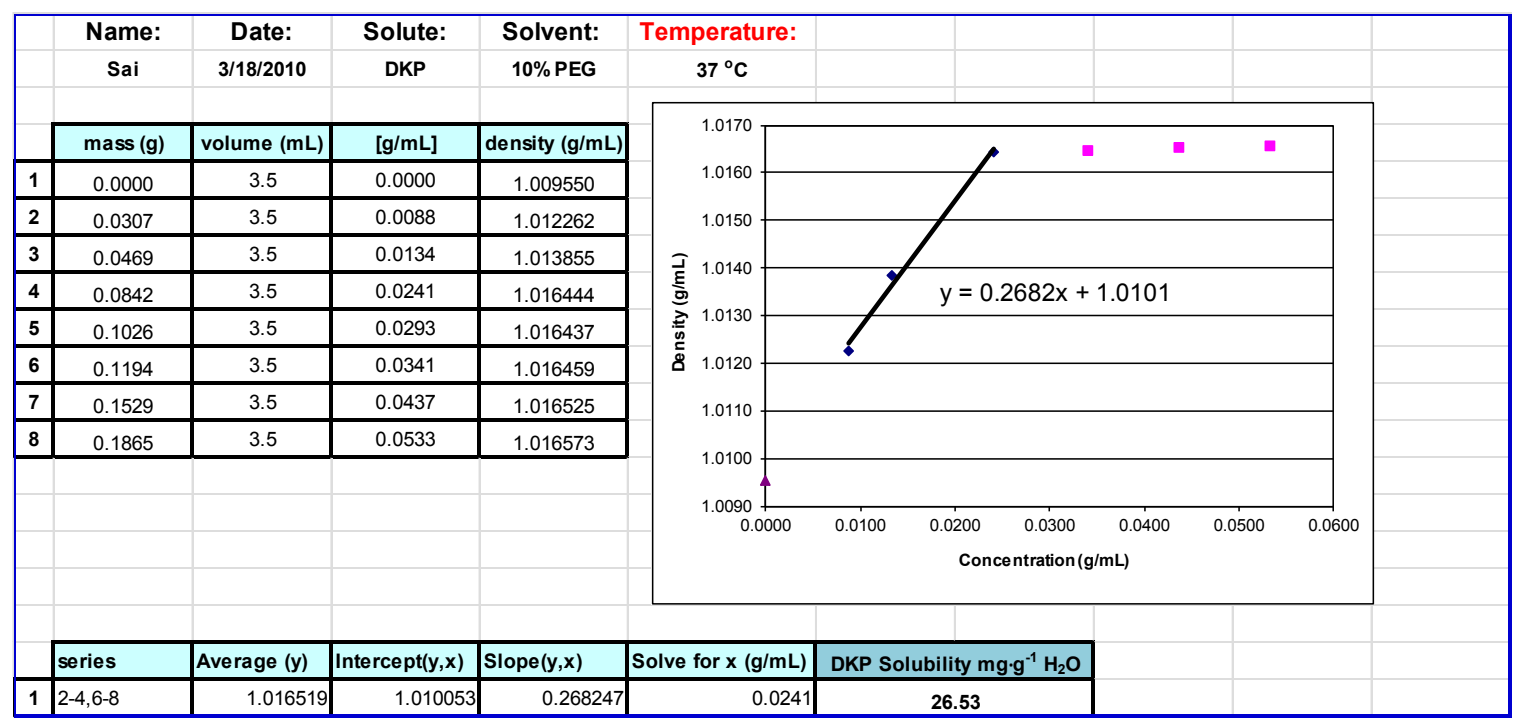

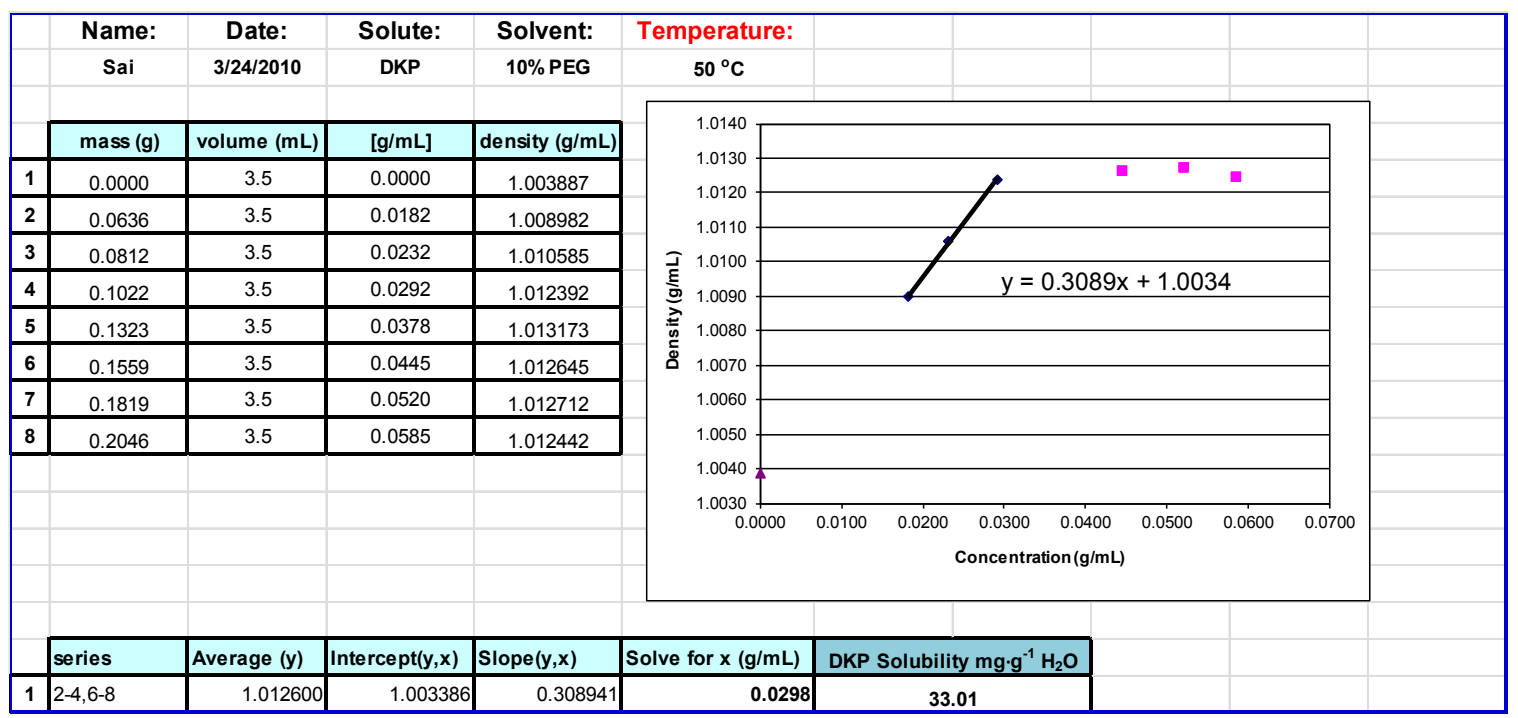




\section{0\% Dextran Representative Data}

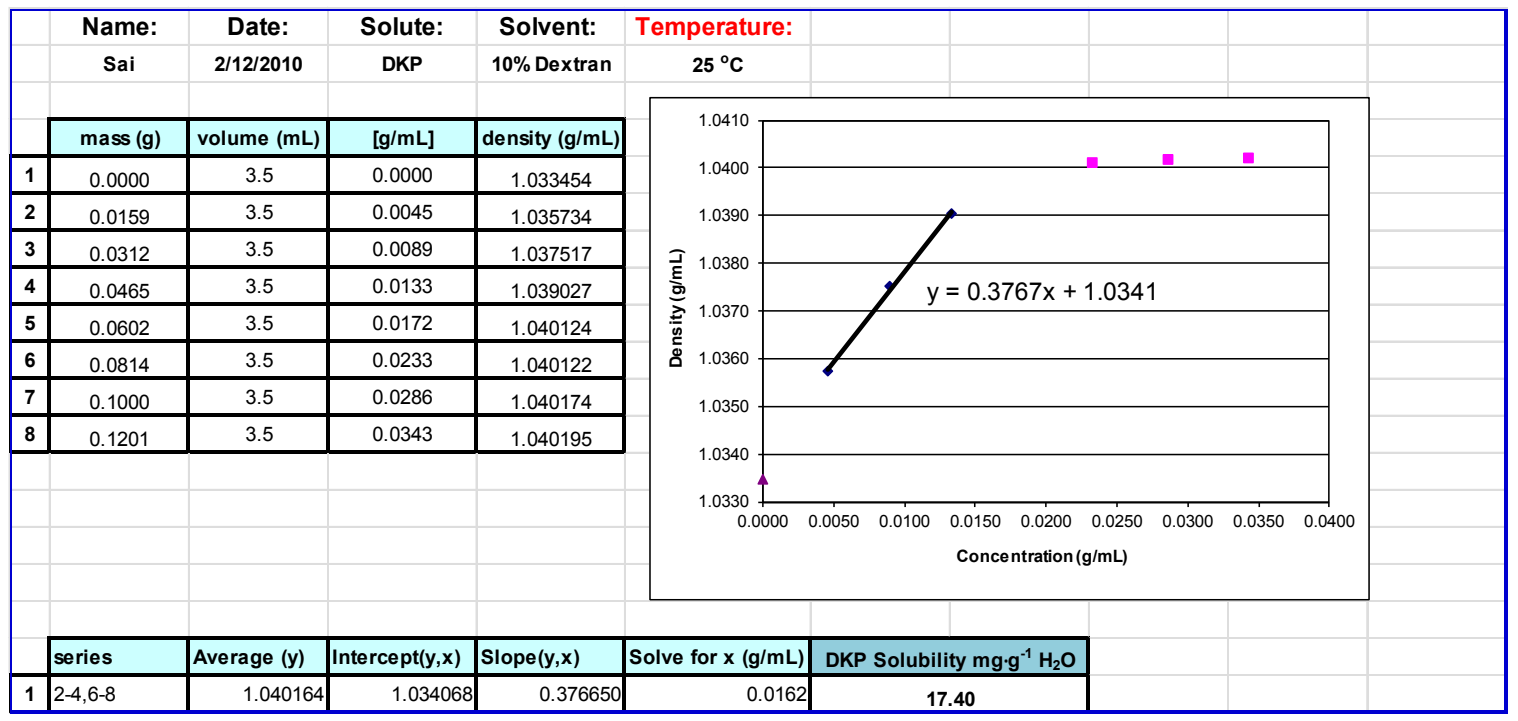

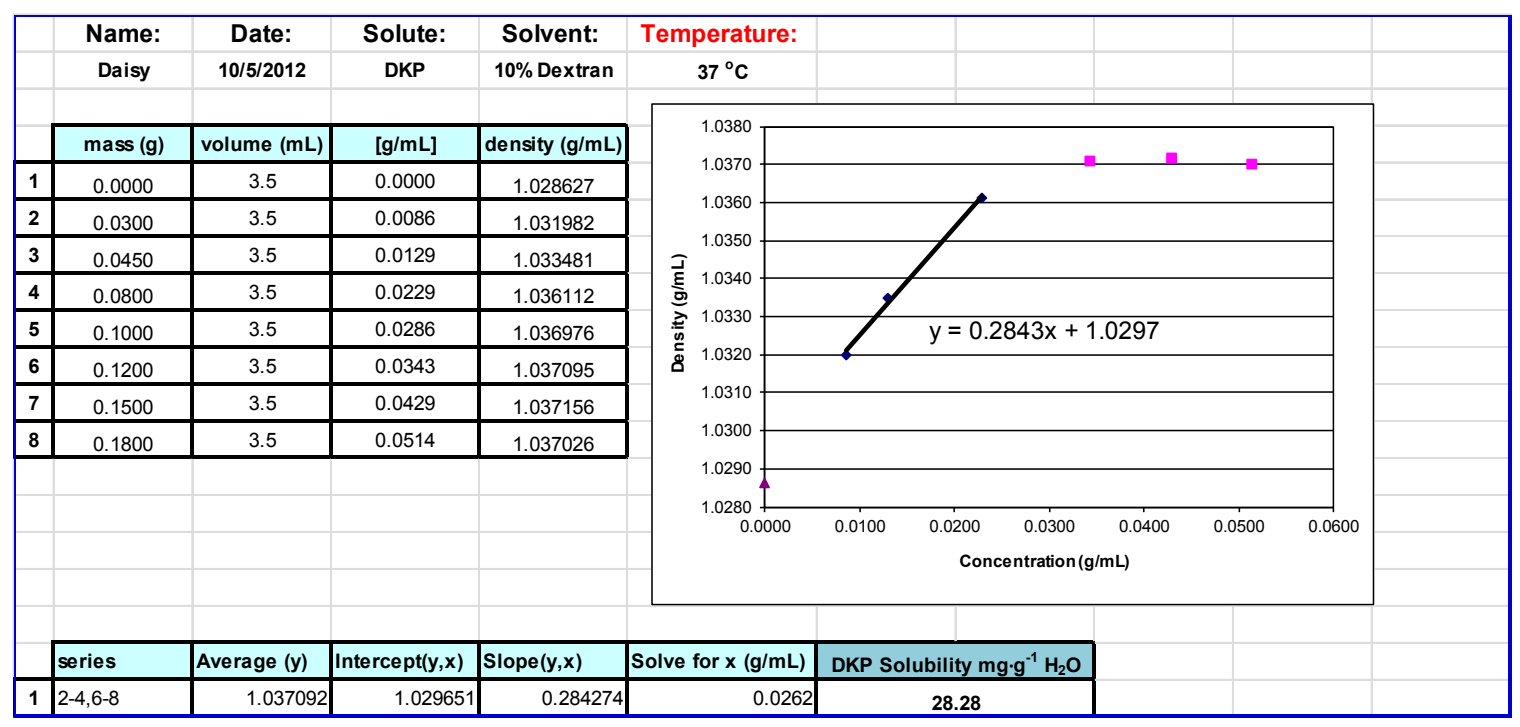




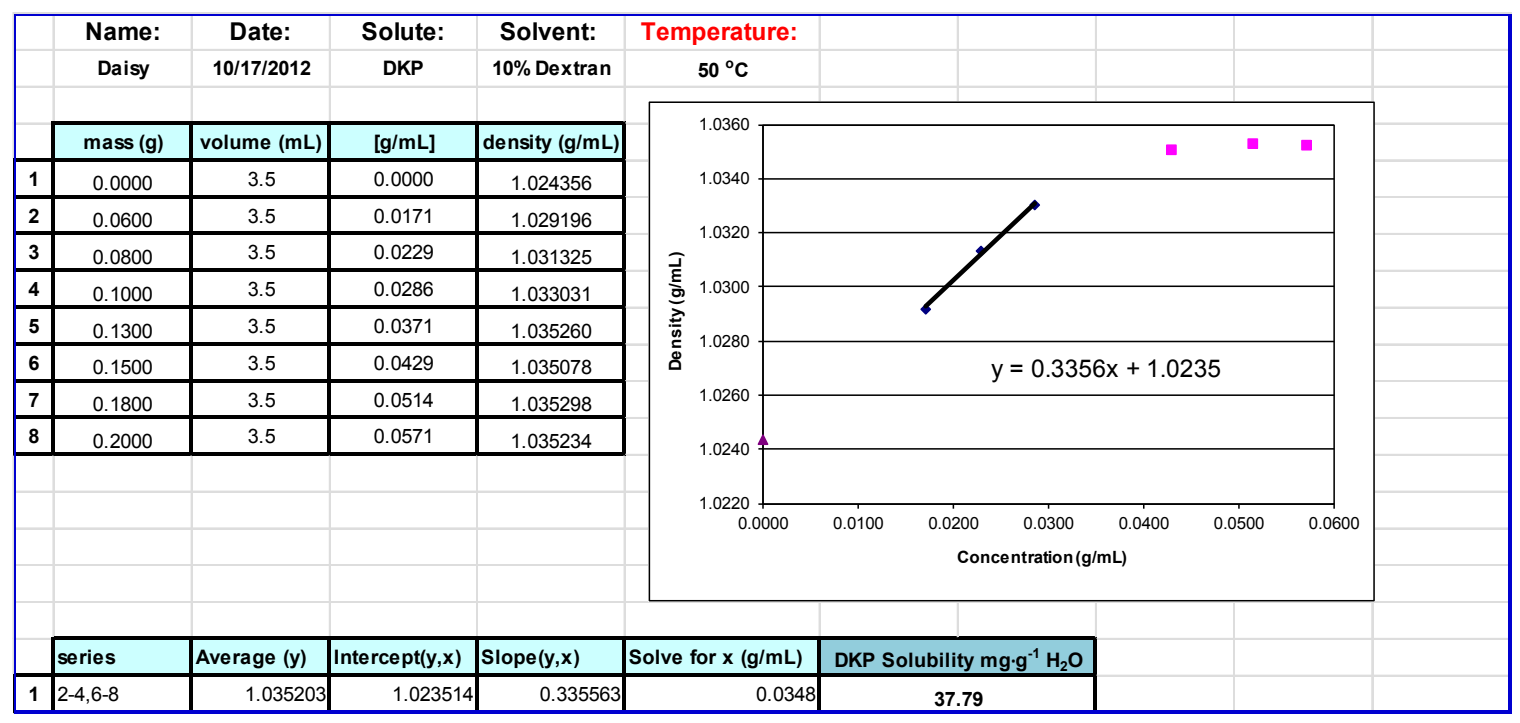

\section{5\% Dextran Representative Data}

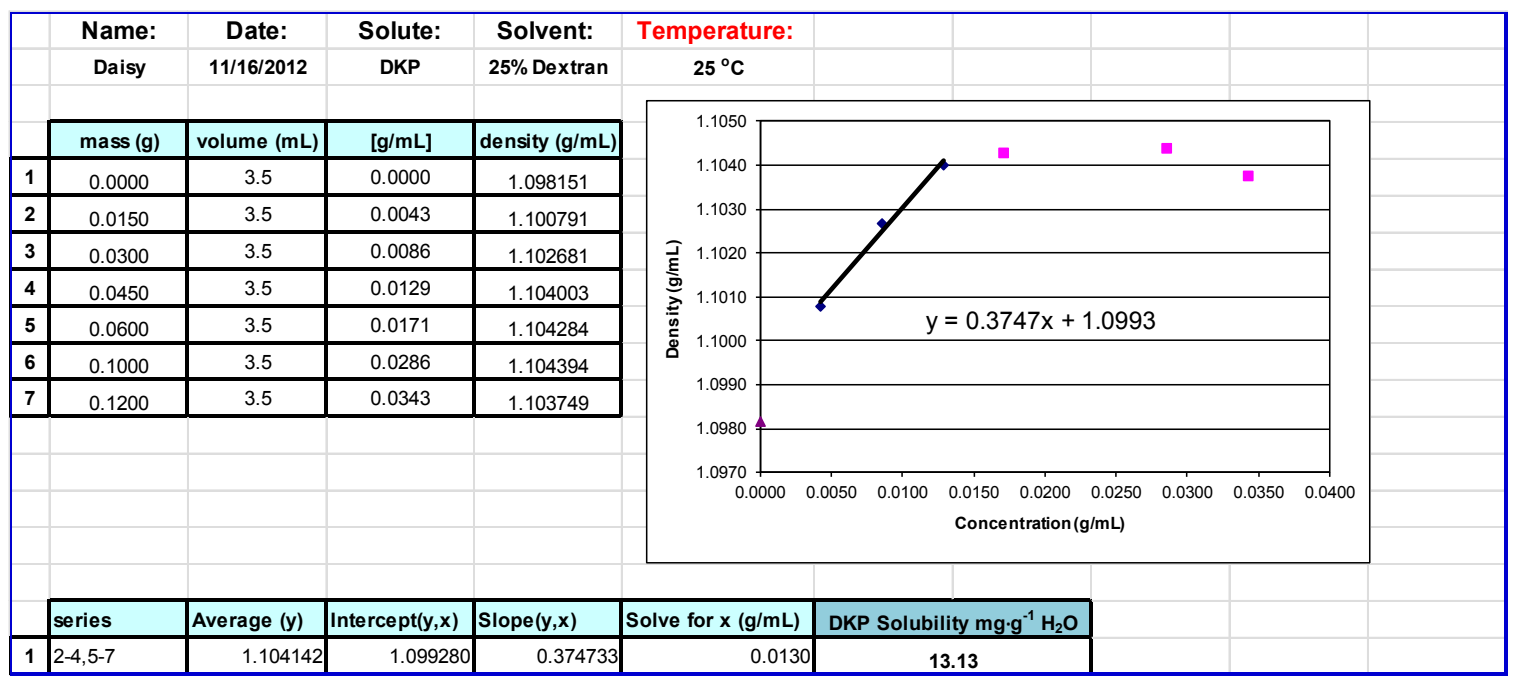




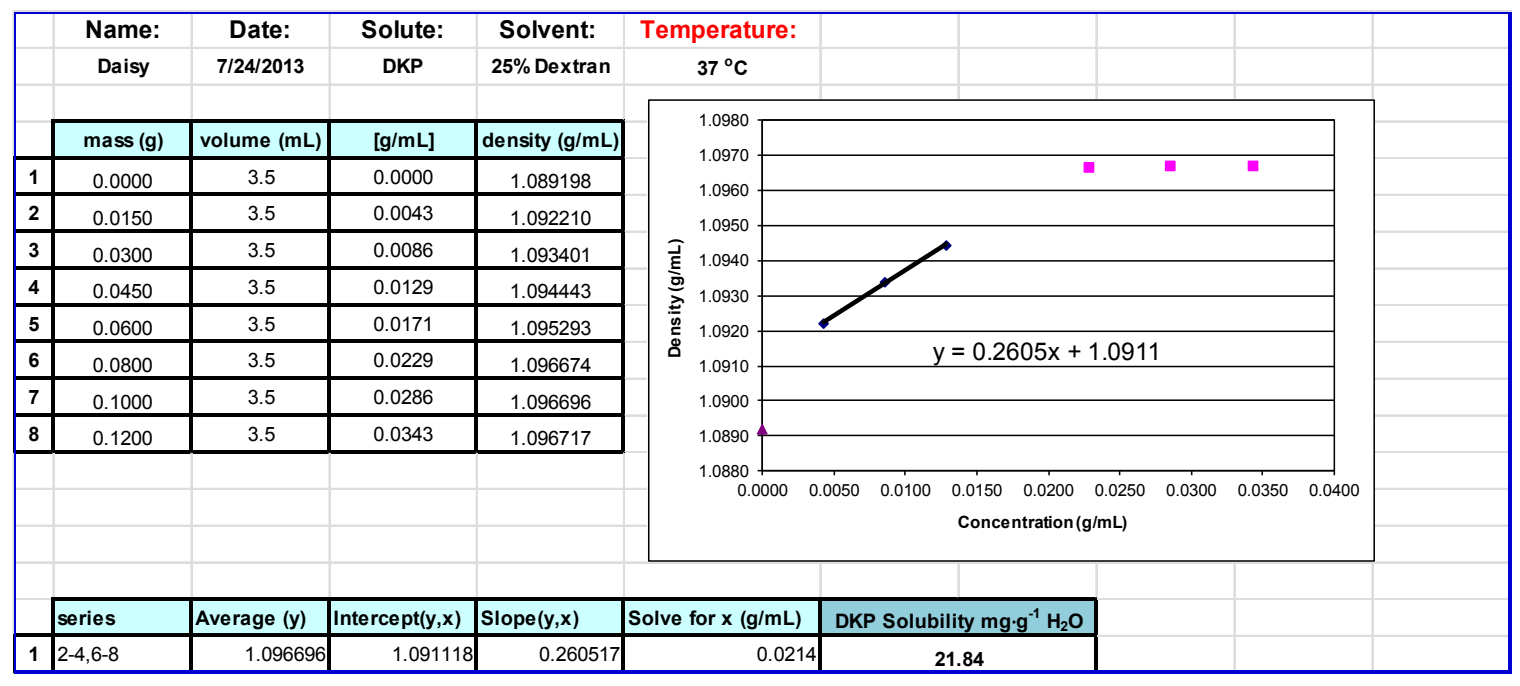

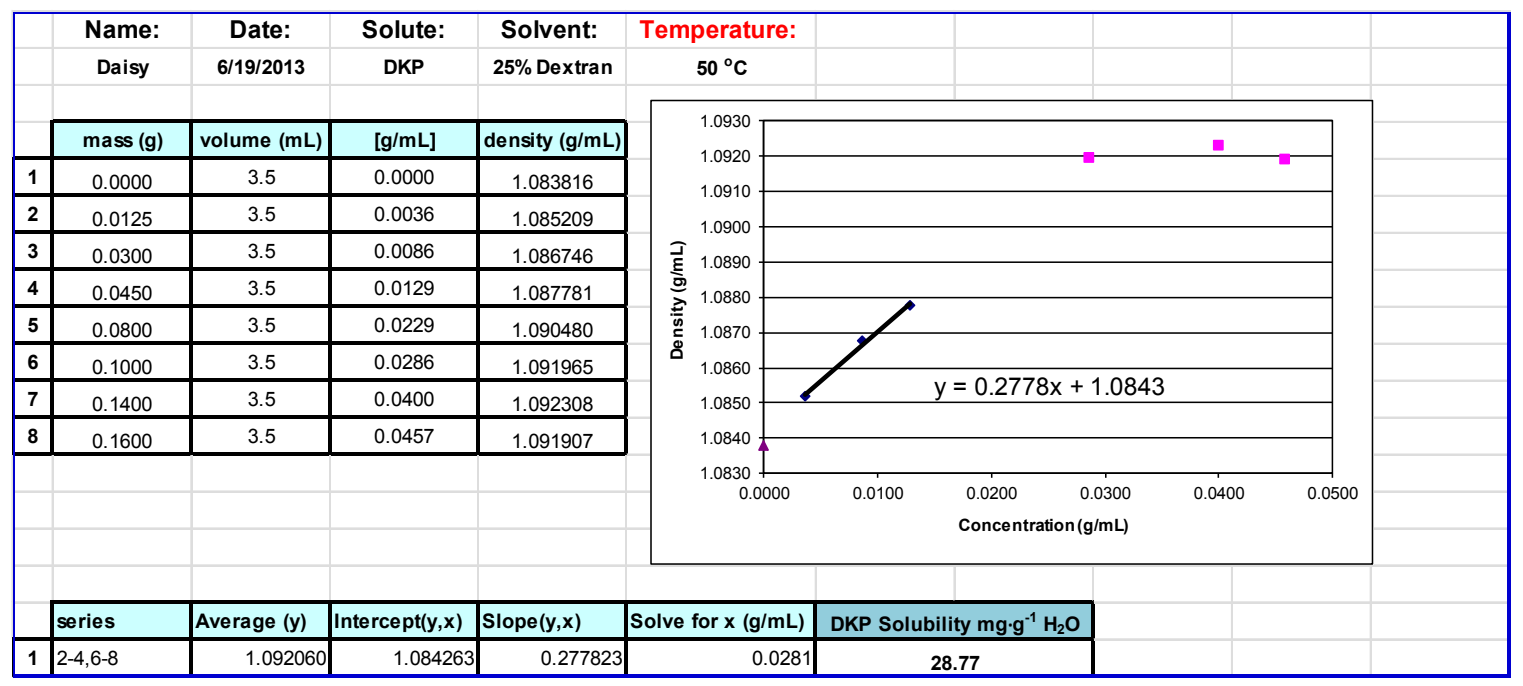




\section{0\% PVP Representative Data}

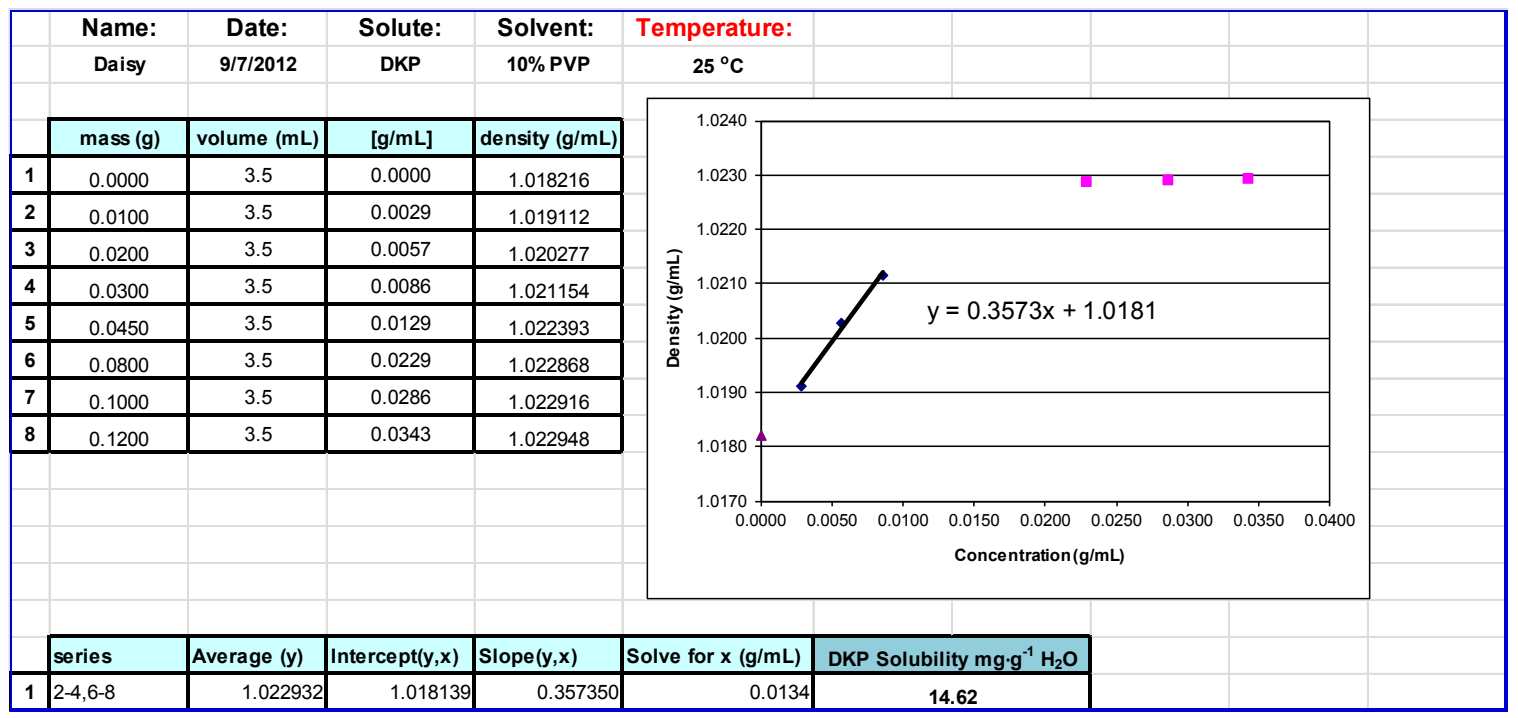

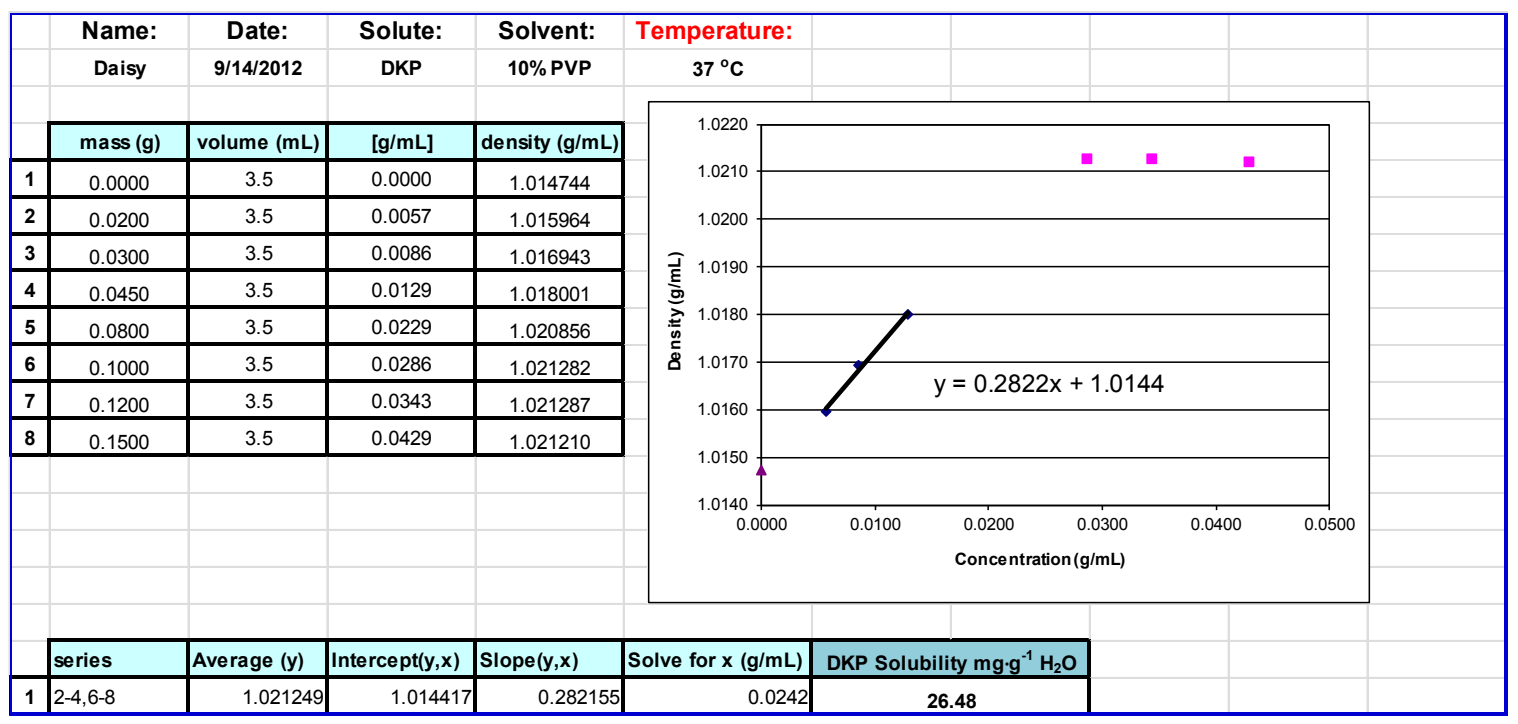




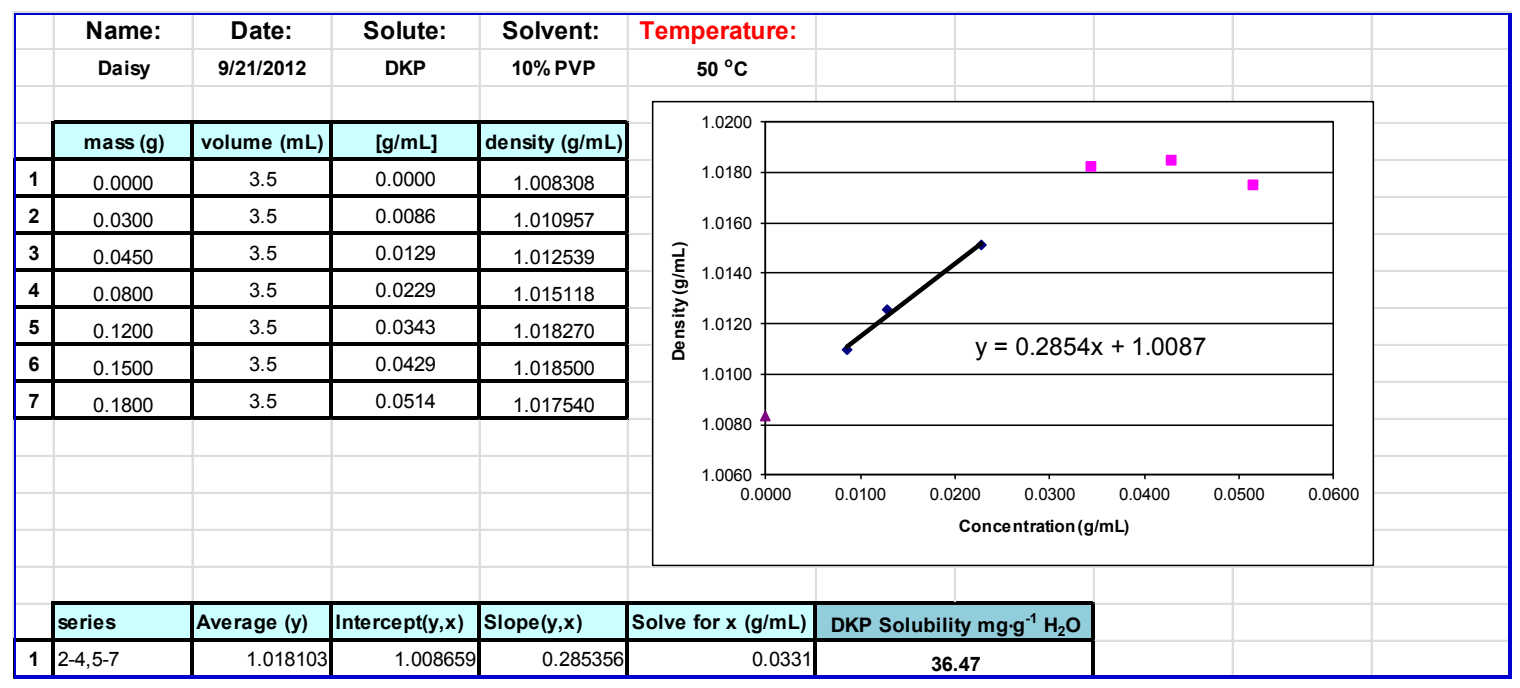

\section{5\% PVP Representative Data}

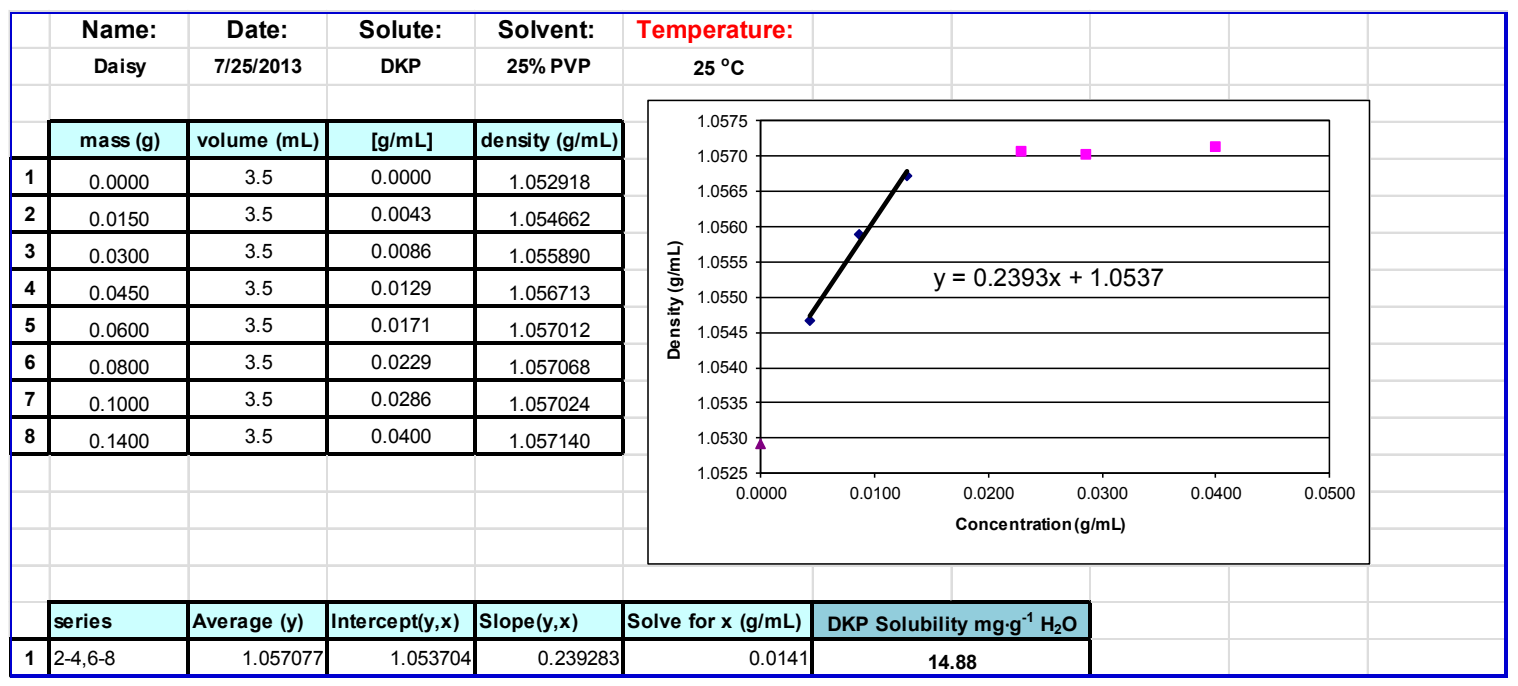




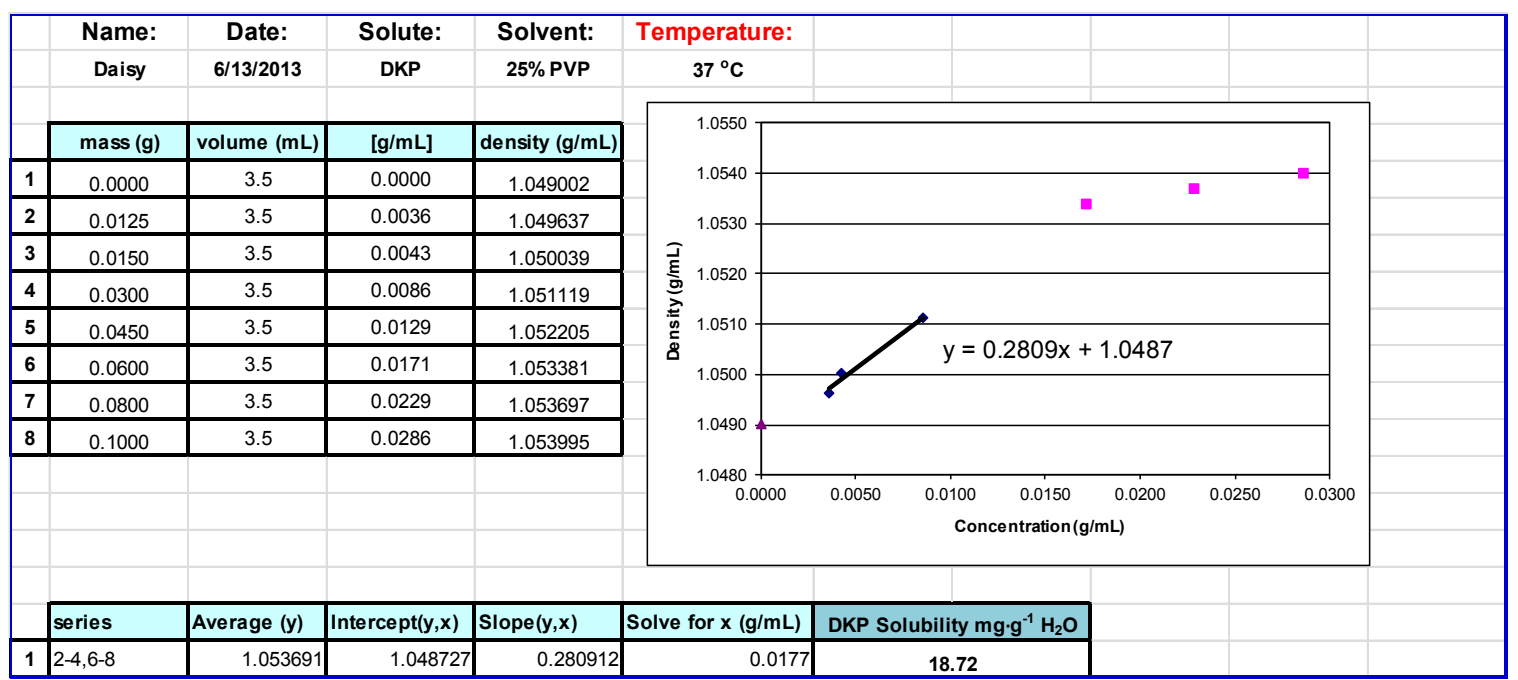

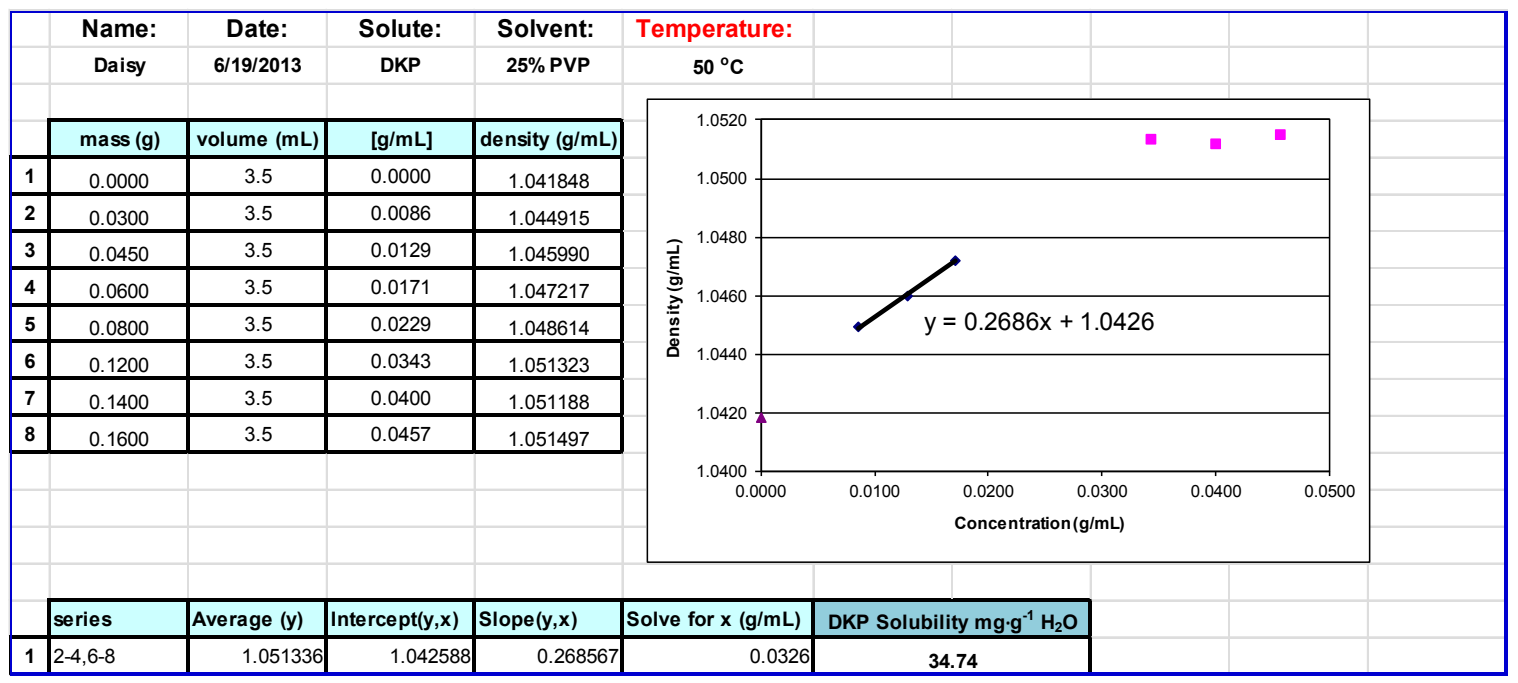


Appendix B. Binding Studies Raw Data \& Results

10\% Ficoll 70 Detailed Data

\begin{tabular}{|c|c|c|c|c|c|c|}
\hline \multicolumn{7}{|c|}{$\left[\right.$ EDTA] \& $\left[\mathrm{CaCl}_{2}\right]$ : Binding Study } \\
\hline Solution & Name & Date & $\mathbf{N}$ & $\mathrm{K} \times 10^{6}$ & $\pm 10^{6}$ & $\begin{array}{c}\Delta \mathrm{H} \\
(\mathrm{cal} / \mathrm{mol})\end{array}$ \\
\hline $10 \%$ Ficoll 70 & Sai & $07 / 14 / 12$ & 0.873 & 1.50 & 0.07 & -4162 \\
\hline $25^{\circ} \mathrm{C}$ & Sai & $07 / 16 / 12$ & 0.801 & 1.43 & 0.08 & -4240 \\
\hline \multirow[t]{2}{*}{$0.5 \mathrm{mM} / 5 \mathrm{mM}$} & Sai & $07 / 20 / 12$ & 0.786 & 1.51 & 0.07 & -4221 \\
\hline & AVE & & & 1.48 & & -4208 \\
\hline \multicolumn{4}{|c|}{ Ave Error } & \multicolumn{2}{|l|}{0.03} & 30 \\
\hline Solution & Name & Date & $\mathbf{N}$ & $K \times 10^{6}$ & $\pm 10^{6}$ & $\begin{array}{c}\Delta H \\
\text { (cal } / \mathrm{mol})\end{array}$ \\
\hline $10 \%$ Ficoll 70 & Sai & $08 / 04 / 12$ & 0.949 & 2.53 & 0.38 & -4446 \\
\hline $25^{\circ} \mathrm{C}$ & Sai & $08 / 05 / 12$ & 0.929 & 2.70 & 0.94 & -4452 \\
\hline \multirow[t]{2}{*}{$2.5 \mathrm{mM} / 25 \mathrm{mM}$} & Sai & 08/10/12 & 0.933 & 2.88 & 0.11 & -4456 \\
\hline & AVE & & & 2.70 & & -4451 \\
\hline \multicolumn{4}{|c|}{ Ave Error } & \multicolumn{2}{|l|}{0.12} & 4 \\
\hline Solution & Name & Date & $\mathbf{N}$ & $\mathrm{K} \times 10^{3}$ & $\pm 10^{3}$ & $\begin{array}{c}\Delta \mathrm{H} \\
(\mathrm{cal} / \mathrm{mol})\end{array}$ \\
\hline $10 \%$ Ficoll 70 & Sai & $05 / 25 / 14$ & 0.754 & 2.54 & 0.18 & -4767 \\
\hline $25^{\circ} \mathrm{C}$ & Sai & $05 / 31 / 14$ & 0.798 & 2.72 & 0.18 & -4785 \\
\hline \multirow[t]{2}{*}{$7.5 \mathrm{mM} / 75 \mathrm{mM}$} & Sai & $06 / 01 / 14$ & 0.809 & 2.74 & 0.18 & -4778 \\
\hline & $A V E$ & & & 2.67 & & -4777 \\
\hline \multicolumn{3}{|c|}{ Ave Error } & \multicolumn{3}{|c|}{0.08} & 6 \\
\hline Solution & Name & Date & $\mathbf{N}$ & $K \times 10^{4}$ & $\pm 10^{4}$ & $\begin{array}{c}\Delta H \\
\text { (cal } / \mathrm{mol})\end{array}$ \\
\hline $10 \%$ Ficoll 70 & Sai & $06 / 14 / 14$ & 0.889 & 2.65 & 0.04 & -4478 \\
\hline $25^{\circ} \mathrm{C}$ & Sai & $06 / 15 / 14$ & 0.878 & 2.68 & 0.05 & -4460 \\
\hline \multirow[t]{2}{*}{$12.5 \mathrm{mM} / 125 \mathrm{mM}$} & Sai & $06 / 21 / 14$ & 0.871 & 1.93 & 0.12 & -4709 \\
\hline & $A V E$ & & & 2.42 & & -4549 \\
\hline \multicolumn{3}{|c|}{ Ave Error } & & 0.03 & & 30 \\
\hline
\end{tabular}


10\% PVP Detailed Data

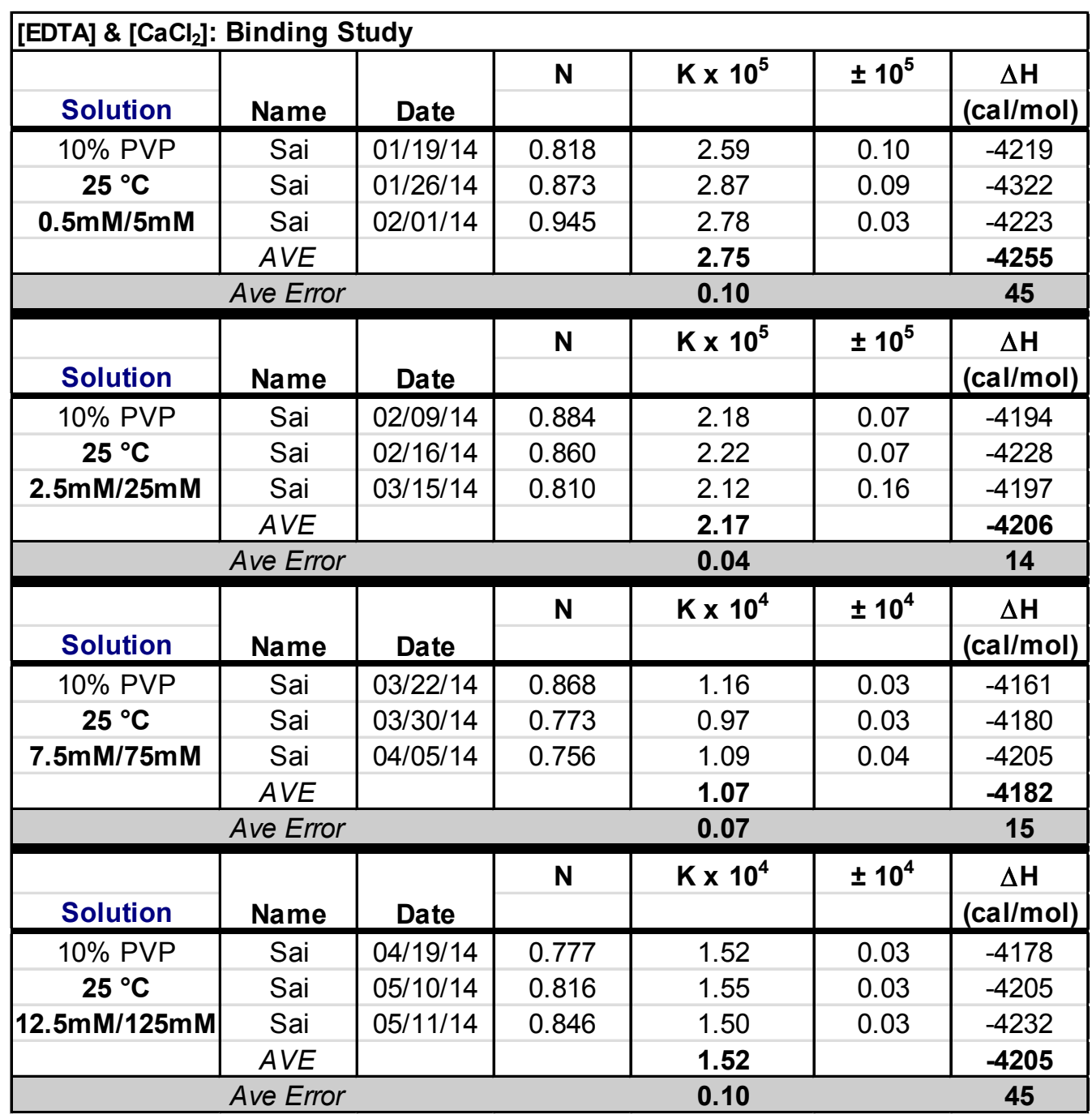

10\% Dextran Detailed Data

\begin{tabular}{|c|c|c|c|c|c|c|}
\hline \multicolumn{7}{|c|}{ [EDTA] \& [ $\left.\mathrm{CaCl}_{2}\right]$ : Binding Study } \\
\hline \multirow[b]{2}{*}{ Solution } & \multirow[b]{2}{*}{ Name } & \multirow[b]{2}{*}{ Date } & \multirow[t]{2}{*}{$\mathbf{N}$} & \multirow[t]{2}{*}{$\mathrm{K} \times 10^{5}$} & \multirow[t]{2}{*}{ $\pm 10^{5}$} & \multirow{2}{*}{$\begin{array}{c}\Delta H \\
\text { (cal } / \mathrm{mol})\end{array}$} \\
\hline & & & & & & \\
\hline & Sai & $09 / 02 / 13$ & 0.728 & 8.91 & 0.52 & -4511 \\
\hline 10\% Dextran & Sai & $09 / 08 / 13$ & 0.877 & 7.11 & 0.31 & -4617 \\
\hline $25^{\circ} \mathrm{C}$ & Sai & $09 / 21 / 13$ & 0.799 & 7.93 & 0.43 & -4598 \\
\hline $0.5 \mathrm{mM} / 5 \mathrm{mM}$ & $A V E$ & & & 7.98 & & -4575 \\
\hline & Ave Errc & & & 0.62 & & 43 \\
\hline
\end{tabular}




\section{Results to Chart from Binding Studies}

\begin{tabular}{|c|c|c|c|c|c|c|c|c|c|c|c|c|}
\hline \multirow{2}{*}{$\begin{array}{c}{\left[\mathrm{Ca}^{2+}: \text { EDTA }\right]} \\
\text { Complex }\end{array}$} & & $\begin{array}{l}\text { Control } \\
\text { Average }\end{array}$ & & $10 \%$ & $\begin{array}{c}\% \text { Ficoll } 7 \\
\text { Average }\end{array}$ & & & $\begin{array}{l}10 \% \text { PVP } \\
\text { Average }\end{array}$ & & & $\begin{array}{l}\text { 0\% Dextr } \\
\text { Average }\end{array}$ & \\
\hline & $K \times 10^{5}$ & Error of $\mathrm{K}$ & $-R T \operatorname{lnK}$ & $K \times 10^{5}$ & Error of $\mathrm{I}$ & -RTInK & $K \times 10^{5}$ & Error of $\mathrm{K}$ & $-R T \operatorname{lnk}$ & $K \times 10^{5}$ & Error of $\mathrm{K}$ & RTInK \\
\hline 0.5 & 13.4 & 0.30 & -3.63 & 14.8 & 0.03 & -8.42 & 2.75 & 0.10 & -7.42 & 7.98 & 0.62 & -8.05 \\
\hline 2.5 & 10.6 & 0.30 & -3.57 & 27.0 & 0.12 & -8.77 & 2.17 & 0.04 & -7.28 & & & \\
\hline 7.5 & 6.58 & 0.29 & -3.45 & 0.0267 & 0.08 & -4.67 & 1.07 & 0.07 & -5.50 & & & \\
\hline 12.5 & 4.48 & 0.14 & -3.35 & 0.242 & 0.03 & -5.98 & 1.52 & 0.1 & -5.70 & & & \\
\hline
\end{tabular}

\section{Appendix C. Dilution Studies Raw Data \& Results}

\begin{tabular}{|c|c|c|c|c|c|c|c|c|c|c|c|c|c|}
\hline \multirow{2}{*}{ 10\% Dextran } & \multicolumn{3}{|c|}{ First Trial } & \multicolumn{4}{|c|}{ Second Trial } & \multicolumn{3}{|c|}{ Third Trial } & \multicolumn{3}{|c|}{ Average from Trials } \\
\hline & \multicolumn{13}{|c|}{$\Delta \mathrm{H}\left(\mu \mathrm{Cal}\right.$ per $\mu \mathrm{L}$ of $\left.\mathrm{H}_{2} \mathrm{O}\right)$} \\
\hline injection & $\underline{25}{ }^{\circ} \mathrm{C}$ & $37^{\circ} \mathrm{C}$ & $\underline{50}{ }^{\circ} \mathrm{C}$ & $\underline{5{ }^{\circ} \mathrm{C}}$ & $\underline{25}{ }^{\circ} \mathrm{C}$ & $37^{\circ} \mathrm{C}$ & $\underline{50{ }^{\circ} \mathrm{C}}$ & $25^{\circ} \mathrm{C}$ & $37^{\circ} \mathrm{C}$ & $50^{\circ} \mathrm{C}$ & $25^{\circ} \mathrm{C}$ & $37^{\circ} \mathrm{C}$ & $\underline{50{ }^{\circ} \mathrm{C}}$ \\
\hline third from last & -21.2 & -17.4 & -9.0 & -22.3 & -19.7 & -16.3 & -8.7 & -20.2 & -17.0 & -9.2 & -20.4 & -16.9 & -8.8 \\
\hline second from last & -21.7 & -17.9 & -9.1 & -22.8 & -20.2 & -16.0 & -9.0 & -19.7 & -17.5 & -9.1 & \multicolumn{3}{|c|}{ Average Error from Trials } \\
\hline last & -20.9 & -16.5 & -7.4 & -22.4 & -19.8 & -16.7 & -9.2 & -19.9 & -17.2 & -8.9 & $\underline{25^{\circ} \mathrm{C}}$ & $37^{\circ} \mathrm{C}$ & $50^{\circ} \mathrm{C}$ \\
\hline Average & -21.3 & -17.3 & -8.5 & -22.5 & -19.9 & -16.3 & -9.0 & -19.9 & -17.2 & -9.1 & 0.6 & 0.4 & 0.2 \\
\hline
\end{tabular}

\begin{tabular}{|c|c|c|c|c|c|c|c|c|c|c|c|c|c|}
\hline \multirow{2}{*}{$10 \%$ Ficoll 70} & \multicolumn{3}{|c|}{ First Trial } & \multicolumn{4}{|c|}{ Second Trial } & \multicolumn{3}{|c|}{ Third Trial } & \multicolumn{3}{|c|}{ Average from Trials } \\
\hline & \multicolumn{13}{|c|}{$\Delta \mathrm{H}\left(\mu \mathrm{Cal}\right.$ per $\mu \mathrm{L}$ of $\left.\mathrm{H}_{2} \mathrm{O}\right)$} \\
\hline injection & $25^{\circ} \mathrm{C}$ & $37^{\circ} \mathrm{C}$ & $50^{\circ} \mathrm{C}$ & $5^{\circ} \mathrm{C}$ & $25^{\circ} \mathrm{C}$ & $37^{\circ} \mathrm{C}$ & $50^{\circ} \mathrm{C}$ & $25^{\circ} \mathrm{C}$ & $37^{\circ} \mathrm{C}$ & $50^{\circ} \mathrm{C}$ & $25^{\circ} \mathrm{C}$ & $37^{\circ} \mathrm{C}$ & $50^{\circ} \mathrm{C}$ \\
\hline \multirow{3}{*}{$\begin{array}{r}\text { third from last } \\
\text { second from last } \\
\text { last }\end{array}$} & -3.6 & -3.5 & -3.9 & -3.5 & -5.3 & -5.0 & -4.1 & -3.7 & -4.7 & -3.8 & -4.0 & -4.4 & -3.9 \\
\hline & -3.5 & -3.4 & -3.5 & -3.8 & -5.3 & -4.8 & -4.5 & -3.2 & -5.0 & -4.0 & \multicolumn{3}{|c|}{ Average Error from Trials } \\
\hline & -3.4 & -3.6 & -3.4 & -3.4 & -4.6 & -4.9 & -4.3 & -3.4 & -4.9 & -3.9 & $25^{\circ} \mathrm{C}$ & $37^{\circ} \mathrm{C}$ & $50^{\circ} \mathrm{C}$ \\
\hline Average & -3.5 & -3.5 & -3.6 & -3.6 & -5.1 & -4.9 & -4.3 & -3.4 & -4.9 & -3.9 & 0.7 & 0.6 & 0.2 \\
\hline
\end{tabular}

\begin{tabular}{|c|c|c|c|c|c|c|c|c|c|c|c|c|c|}
\hline \multirow{2}{*}{$10 \%$ PEG } & \multicolumn{3}{|c|}{ First Trial } & \multicolumn{4}{|c|}{ Second Trial } & \multicolumn{3}{|c|}{ Third Trial } & \multicolumn{3}{|c|}{ Average from Trials } \\
\hline & \multicolumn{13}{|c|}{$\Delta \mathrm{H}\left(\mu \mathrm{Cal}\right.$ per $\mu \mathrm{L}$ of $\left.\mathrm{H}_{2} \mathrm{O}\right)$} \\
\hline injection & $25^{\circ} \mathrm{C}$ & $37^{\circ} \mathrm{C}$ & $50^{\circ} \mathrm{C}$ & $5^{\circ} \mathrm{C}$ & $25^{\circ} \mathrm{C}$ & $37^{\circ} \mathrm{C}$ & $50^{\circ} \mathrm{C}$ & $25^{\circ} \mathrm{C}$ & $37^{\circ} \mathrm{C}$ & $50^{\circ} \mathrm{C}$ & $25^{\circ} \mathrm{C}$ & $37^{\circ} \mathrm{C}$ & $50^{\circ} \mathrm{C}$ \\
\hline third from last & -145.0 & -132.1 & -122.5 & $\mid-148.7$ & -131.3 & -123.7 & -199.5 & $\mid-136.3$ & -127.5 & -119.4 & -135.4 & -127.9 & -121.0 \\
\hline second from last & -137.1 & -126.8 & -122.1 & -145.7 & -129.8 & -125.7 & -121.8 & $\mid-133.4$ & -126.6 & -119.1 & Average & E Error fron & $n$ Trials \\
\hline last & -139.1 & -135.0 & -128.0 & $\mid-147.1$ & -132.4 & -125.5 & -116.6 & -134.6 & -128.3 & -119.9 & $25^{\circ} \mathrm{C}$ & $37^{\circ} \mathrm{C}$ & $50^{\circ} \mathrm{C}$ \\
\hline Average & -140.4 & -131.3 & -124.2 & -147.2 & -131.2 & -125.0 & -119.3 & -134.8 & -127.5 & -119.5 & 3.3 & 2.3 & 2.1 \\
\hline
\end{tabular}

\begin{tabular}{|c|c|c|c|c|c|c|c|c|c|c|c|c|c|}
\hline \multirow{2}{*}{$10 \%$ PVP } & \multicolumn{3}{|c|}{ First Trial } & \multicolumn{4}{|c|}{ Second Trial } & \multicolumn{3}{|c|}{ Third Trial } & \multicolumn{3}{|c|}{ Average from Trials } \\
\hline & \multicolumn{13}{|c|}{$\Delta \mathrm{H}\left(\mu \mathrm{Cal}\right.$ per $\mu \mathrm{L}$ of $\left.\mathrm{H}_{2} \mathrm{O}\right)$} \\
\hline injection & $25^{\circ} \mathrm{C}$ & $37^{\circ} \mathrm{C}$ & $50^{\circ} \mathrm{C}$ & $5{ }^{\circ} \mathrm{C}$ & $25^{\circ} \mathrm{C}$ & $37^{\circ} \mathrm{C}$ & $50^{\circ} \mathrm{C}$ & $25^{\circ} \mathrm{C}$ & $37^{\circ} \mathrm{C}$ & $50^{\circ} \mathrm{C}$ & $25^{\circ} \mathrm{C}$ & $37^{\circ} \mathrm{C}$ & $\underline{50{ }^{\circ} \mathrm{C}}$ \\
\hline third from last & -26.8 & -40.2 & -39.1 & -28.7 & -27.1 & -42.0 & -38.5 & -27.2 & -41.7 & -39.5 & -27.0 & -41.7 & -39.0 \\
\hline second from last & -27.4 & -40.7 & -38.8 & -29.3 & -27.4 & -42.9 & -38.9 & -26.4 & -42.1 & -39.2 & Avera & Errorfro & Trials \\
\hline last & -25.0 & -40.6 & -39.3 & -30.6 & -27.9 & -42.7 & -39.0 & -28.0 & -42.7 & -39.0 & $25^{\circ} \mathrm{C}$ & $37^{\circ} \mathrm{C}$ & $50^{\circ} \mathrm{C}$ \\
\hline Average & -26.4 & -40.5 & -39.1 & -29.5 & -27.5 & -42.5 & -38.8 & -27.2 & -42.2 & -39.2 & 0.4 & 0.8 & 0.2 \\
\hline
\end{tabular}

